\title{
Progress in Graphene/Metal Oxide Composite Photocatalysts for Degradation of Organic Pollutants
}

\author{
Xiaodong Hong ${ }^{1, *}, \mathrm{Xu} \mathrm{Wang}^{2}$, Yang $\mathrm{Li}^{2}$, Jiawei Fu ${ }^{2}$ and Bing Liang ${ }^{3}$ \\ 1 School of Materials Science and Hydrogen Energy, Foshan University, Foshan 528000, China \\ 2 College of Materials Science and Engineering, Liaoning Technical University, Fuxin 123000, China; \\ MeliaRoelofsVl@gmail.com (X.W.); ly940828@gmail.com (Y.L.); fjw1518816615@gmail.com (J.F.) \\ 3 College of Materials Science and Engineering, Shenyang University of Chemical Technology, \\ Shenyang 110142, China; liangbing@syuct.edu.cn \\ * Correspondence: hongxiaodong@Intu.edu.cn; Tel.: +86-138-4187-7730
}

Received: 4 July 2020; Accepted: 7 August 2020; Published: 11 August 2020

check for updates

\begin{abstract}
The sewage discharge of industrial wastewater seriously pollutes the water source and rivers, which is very harmful to the health of humans and wildlife. Among those methods for treating wastewater, photocatalysis is a sustainable and environmental-friendly technique for removing the organic pollutants with no secondary pollution. As a popular photocatalyst, graphene/metal oxide nanocomposites have been widely reported in the photocatalysis field. In this review, the recent progress of graphene/metal oxide composites including binary and ternary composites is summarized in detail. The synthesis, microstructure design, and application performance of graphene/ $\mathrm{TiO}_{2}$, graphene/ZnO, graphene $/ \mathrm{SnO}_{2}$, graphene $/ \mathrm{WO}_{3}$, graphene/ $\mathrm{Fe}_{2} \mathrm{O}_{3}$, and graphene $/ \mathrm{Cu}_{2} \mathrm{O}$ composites are introduced firstly. Then, the synthesis, the selection of components, and the performance of various ternary composites are summarized specifically, including graphene $/ \mathrm{TiO}_{2^{-}}$, graphene/ZnO-, graphene/SnO $2^{-}$,

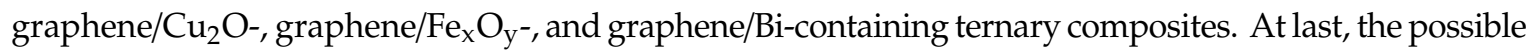
research directions of graphene/metal oxide nanocomposites are put forward. The main purpose is to provide a theoretical guidance for designing high-performance graphene/metal oxide photocatalysts for wastewater treatment.
\end{abstract}

Keywords: photocatalysis; metal oxide; graphene; wastewater treatment

\section{Introduction}

The rapid development of industry accelerates environmental pollution; for example, abundant industrial wastewater or mining wastewater discharges into the soil or rivers, which is very harmful to the health of humans and wildlife. Therefore, the environmental protection and remediation should be paid more attention. In the field of wastewater treatment, various strategies including adsorption, ion change, membrane separation, chemical precipitation, photocatalytic technique, and so on, have been developed for treating different wastewater [1]. Among these methods, photocatalysis is a sustainable and environmental-friendly technique for removing the organic pollutants in wastewater with no secondary pollution. During the photodegradation process of organic pollutants, the powder-like or bulk photocatalysts are put into the wastewater, and the photocatalysts adsorb the organic molecules firstly. Under the irradiation of visible or UV light, when the absorbed light energy is equal to or higher than the band gap of semiconductors, the electrons can be excited from the valence band (VB) to the conduction band (CB); then, the corresponding holes are left behind in the VB [2]. The photoexcited electrons will react with the oxygen adsorbed on the surface of photocatalyst to form superoxide anion $\left(\cdot \mathrm{O}_{2}^{-}\right)$, and the superoxide anions further combine with $\mathrm{H}^{+}$to produce hydroxyl radicals $(\cdot \mathrm{OH})$. Meanwhile, the holes also react with $\mathrm{H}_{2} \mathrm{O}$ to produce hydroxyl radicals $(\cdot \mathrm{OH})$. The hydroxyl radicals 
$(\cdot \mathrm{OH})$ have a strong oxidation capability, and they oxidize the organic molecules into molecular fragmentations or intermediates firstly and then completely oxidize them into $\mathrm{CO}_{2}$ and $\mathrm{H}_{2} \mathrm{O}$ with no other pollutants. Based on the aboved photocatalytic mechanism, the photoexcitation is a prerequiste for a photochemical reaction. Moreover, the photogenerated electrons and holes can be recombined easily on the surface of the semiconductor, which reduces the reaction time between the active radicals and oxygen. Therefore, the expansion of the light absorption by adjusting the band gap is the main strategy to design high-performance semiconductor photocatalysts [3].

In order to enhance the photocatalytic activity of metal oxides, conductive graphene nanosheets are used to transfer the photogenerated electrons rapidly, effectively inhibiting the recombination of photogenerated electrons and holes. Therefore, the photocatalytic mechanism of graphene/metal oxides can be considered as a combination of an excellent transport of graphene and the photocatalysis of metal oxide semiconductors. Under the irradiation of UV or visible light, the electrons derived from metal oxides spontaneously transport into graphene for the high Fermi level of $4.6 \mathrm{eV}$, and the graphene serves as the electrons storage tank to suppress the recombination of electron-hole pairs. In addition, the decoration of metal oxide nanostructures on graphene nanosheets effectively overcomes the aggregation and re-stacking of nanostructures, thereby increasing the specific surface area of the composite. Meanwhile, the functional groups on the graphene surface serve as active sites for adsorbing organic molecules. Therefore, the introduction of graphene significantly improves the photocatalytic performance of metal oxides [4]. In order to design high-performance graphene/metal oxide photocatalysts, except for the selection and microstructure design of metal oxides, the type of graphene is also important for enhancing the photodegradation performance of composites. In the graphene family, conductive graphene, hydrophilic graphene oxides (GO), and modified graphene including heteroatom doping, graphene quantom dots, and a three-dimensional network or framework are widely serving as conductive or active substrate to prepare graphene/metal oxide composite photocatalysts [5].

The controllable synthesis of graphene/metal oxide composites is crucial for their photocatalytic performance. Various methods have been developed to synthesize graphene/metal oxide composites; however, these methods can be classified as chemical methods and physical methods. The chemical methods mainly include liquid phase deposition, the sol-gel method, hydrothermal or solvothermal method, photochemical or electrochemical method, and self-assembly method. Liquid phase deposition is also named as a precipitation method. Under the alkaline condition, metal ions react with $\mathrm{OH}^{-}$to form hydroxides on graphene sheets. After a thermal treatment, graphene/metal oxide composites can be fabricated. The sol-gel method is often adopted to prepare $\mathrm{TiO}_{2}, \mathrm{ZnO}$, and $\mathrm{SnO}_{2}$ nanoparticles, in which the precursors of metal chloride or metal alkoxide undergo a sequence of hydrolysis and polycondensation reactions to produce metal oxides on graphene sheets. The hydrothermal or solvothermal method is widely applied to synthesize graphene-based nanocomposites. Under a high temperature above the boiling point of water or solvent, the sealed reaction vessel creates a high pressure, which induces the ordered arrangement of nanoparticles or graphene sheets. The photochemical method often involves photosensitive precursors; through a photo-excitation reaction, the metal oxides are generated on the graphene surface. The electrochemical method is named as an electrodeposition method; through an electrochemical reaction, metal hydroxides can be deposited on the working electrode. After the thermal treatment, the thin film-based nanocomposites can be fabricated successfully. The self-assembly method is an efficient way to unite micro- and nanoobjects on a macroscopic scale by an electrostatic interaction, which has been applied to prepare various photonic crystals and nanocomposites with an ordered microstructure. Compared to complicated chemical methods, physical methods are often simple; they include physical/mechanical mixing, solution mixing, atomic layer deposition (ALD), and the thermal decomposition method. Physical or solution mixing method is an in situ method to prepare metal oxide-graphene composites. The ALD method takes place on a substrate surface by operating self-restricted reactions, which has the potential to settle down 
nanoparticles on high aspect ratio substrates. Thermal decomposition is the pyrolysis of metal acetates or oxysalts to produce metal oxides on the graphene matrix.

In view of the importance of graphene/metal oxide nanocomposites in the photocatalyis field, herein, we summarize the recent progress of graphene/metal oxide composite photocatalysts in the degradation of organic pollutants. As given in Figure 1, according to the composition of composites, binary and ternary composites are classified firstly. In the section of binary composites, we introduce the synthesis, microstructure design, and the application performance of graphene/ $/ \mathrm{TiO}_{2}$, graphene/ $\mathrm{ZnO}$, graphene $/ \mathrm{SnO}_{2}$, graphene $/ \mathrm{WO}_{3}$, graphene $/ \mathrm{Fe}_{2} \mathrm{O}_{3}$, graphene $/ \mathrm{Cu}_{2} \mathrm{O}$, and other metal oxides. In the section of ternary composites, we specifically summarize the synthesis, selection of components, and the photocatalytic performance of graphene/ $\mathrm{TiO}_{2^{-}}$, graphene/ZnO-, graphene $/ \mathrm{SnO}_{2^{-}}$, graphene $/ \mathrm{Cu}_{2} \mathrm{O}-$, graphene/ $\mathrm{Fe}_{\mathrm{x}} \mathrm{O}_{\mathrm{y}^{-}}$, and graphene/Bi-containing ternary composites. At last, the possible research directions of graphene/metal oxide nanocomposites are put forward. The main purpose is to provide a theoretical guidance for designing high-performance graphene/metal oxide photocatalysts for wastewater treatment.

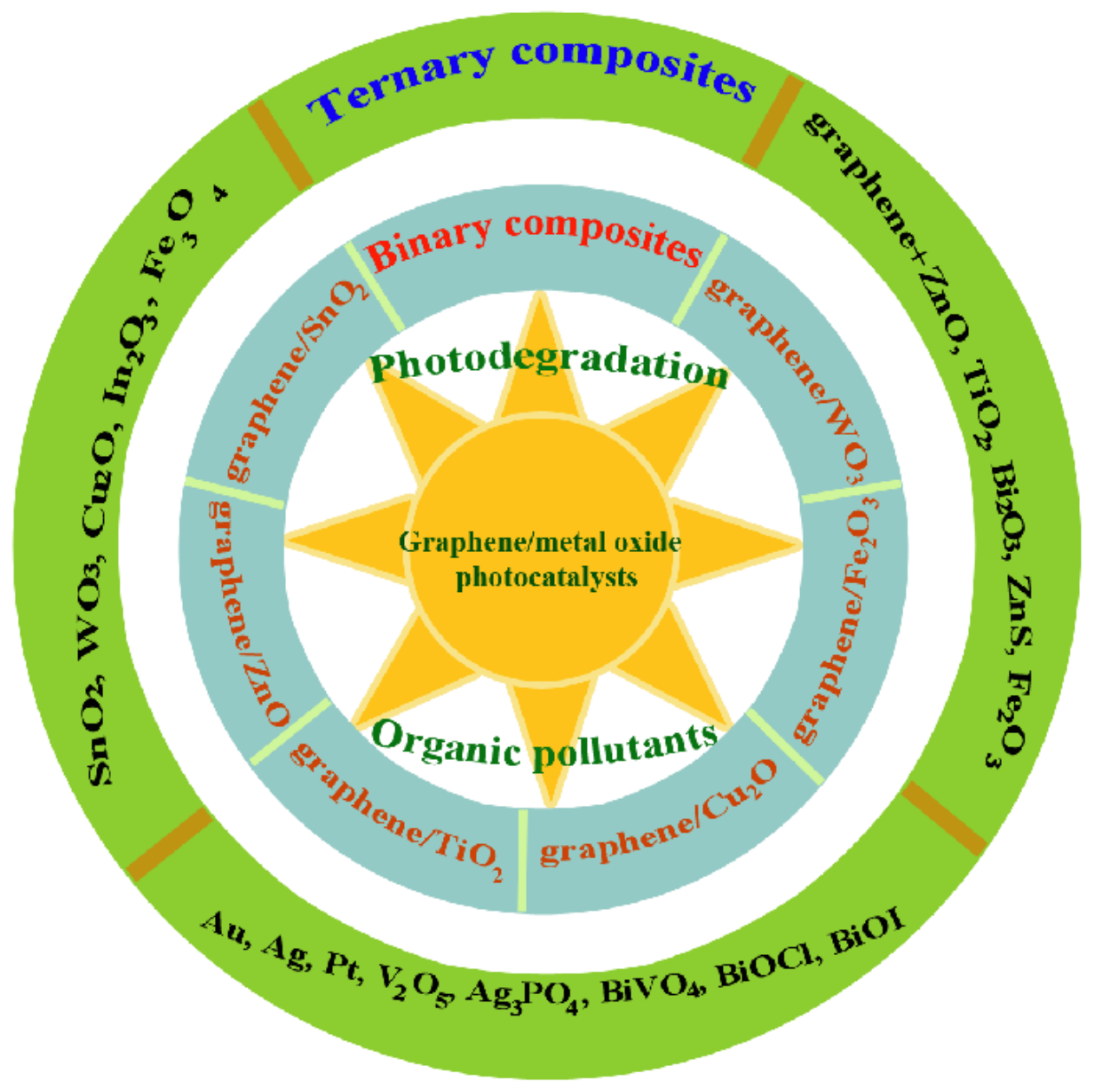

Figure 1. The graphene/metal oxide binary and ternary composite photocatalysts for wastewater treatment.

\section{Graphene/Metal Oxide Binary Composites}

Due to the synergetic effect between graphene sheets and metal oxides, the graphene/metal oxide hybrids show a higher photocatalytic activity than that of individual metal oxides. Therefore, much more efforts have been paid to fabricate various graphene/metal oxide composites through developing new synthetic methods, designing various microstructures, doping them with metal or non-metal atoms, and preparing free-standing frameworks or films. In this section, various graphene/metal oxide binary composites have been introduced, including graphene/ $\mathrm{TiO}_{2}$, graphene/ $\mathrm{ZnO}$, graphene $/ \mathrm{SnO}_{2}$, 
graphene/ $/ \mathrm{WO}_{3}$, graphene/ $\mathrm{Fe}_{2} \mathrm{O}_{3}$, graphene/ $\mathrm{Cu}_{2} \mathrm{O}$, and other metal oxides, such as, $\mathrm{V}_{2} \mathrm{O}_{5}, \mathrm{CeO}_{2}, \mathrm{Nb}_{2} \mathrm{O}_{5}$, $\mathrm{NiO}, \mathrm{Co}_{3} \mathrm{O}_{4}, \mathrm{MoO}_{3}$, and $\mathrm{In}_{2} \mathrm{O}_{3}$.

\subsection{Graphene $/ \mathrm{TiO}_{2}$ Composites}

$\mathrm{TiO}_{2}$ is a typical $n$-type semiconductor that has been widely used in the field of photocatalysis, due to its low cost, easy preparation, and chemical stability [6]. However, the wide band gap of $\mathrm{TiO}_{2}$ limits the light absorption in ultraviolet (UV) light range. In order to expand the light absorption range and suppress the recombination of electron-hole pairs, graphene nanosheets are used to hybridize with $\mathrm{TiO}_{2}$ for improving its photocatalytic activity.

\subsubsection{Controllable Synthesis of $\mathrm{Graphene} / \mathrm{TiO}_{2}$ Composites}

There are lots of methods for synthesizing graphene/ $\mathrm{TiO}_{2}$ composites, such as the hydrothermal or solvothermal method, sol-gel method, photochemical or electrochemical method, liquid phase deposition, physical mixing, etc. Among those methods, hydrothermal or solvothermal reaction has been widely used for synthesizing graphene/ $/ \mathrm{TiO}_{2}$ naocomposites. For instance, Khalid et al. [7] synthesized graphene- $\mathrm{TiO}_{2}$ composite by the hydrothermal method. The composite showed an excellent photocatalytic activity for the degradation of methyl orange (MO), which was due to the extended light absorption range, strong adsorption capacity, and the fast transfer of charge carriers caused by two-dimensional graphene nanosheets. Liang et al. [8] synthesized $\mathrm{TiO}_{2}$ nanocrystals on graphene sheets by a hydrolysis and hydrothermal method for the degradation of Rhodamine $\mathrm{B}$ (Rh B). Liu et al. [9] synthesized $\mathrm{TiO}_{2}$-graphene (P25-GR) composites by a facile solvothermal method. By adjusting the ratio of $\mathrm{P} 25$ and GO, the optimized P25-GR composite delivered a higher photocatalytic activity for the degradation of naphthenic acids (NAs) than pure P25.

Besides the hydrothermal method, Haldorai et al. [10] synthesized $\mathrm{TiO}_{2}$ nanoparticles on an reduced graphene oxide (rGO) surface by an in situ sol-gel method. The nanocomposite exhibited an enhanced photocatalytic activity for degradation of methylene blue (MB). Ton et al. [11] synthesized $\mathrm{TiO}_{2} /$ graphene nanocomposites by the chemical exfoliation of graphite in titanium alkoxide. The graphene sheets were covered with a $\mathrm{TiO}_{2}$ nano-layer, which extended the absorption edge to the visible light region and suppressed the recombination of electron-hole pairs. The novel $\mathrm{TiO}_{2} / g r a p h e n e$ nanocomposite displayed much higher activity for the degradation of $\mathrm{MB}$ than conventional $\mathrm{TiO}_{2} / \mathrm{rGO}$ and $\mathrm{TiO}_{2}-\mathrm{P} 25$.

In addition, the electrospinning method was adopted to obtain a rice-shaped $\mathrm{TiO}_{2}$-graphene composite after sintering [12], as shown in Figure 2a. The one-dimensional composite showed a superior photocatalytic performance for the degradation of MO dye. Furthermore, a UV-assisted photoreduction method was developed to synthesize $\mathrm{TiO}_{2} @ \mathrm{rGO}$ composites (Figure $2 b$ ) by using GO and $\mathrm{TiO}_{2}$ powder (P25) as reactants [13]. The $\mathrm{TiO}_{2} @ \mathrm{rGO}$ "dyade" hybrid exhibited a three times higher photodegradation rate for the removal of rhodamine $6 \mathrm{G}$ than commercial $\mathrm{TiO}_{2}$ due to the enhanced adsorption and the rapid separation of electron and hole. The electrochemical deposition method was developed to prepare $\mathrm{TiO}_{2}$-graphene composite film on Ti substrate [14]. The $\mathrm{TiO}_{2} / \mathrm{GO}$ film presented photocatalytic activity that was almost twice as high as the $\mathrm{TiO}_{2}$ film for the discoloration of Reactive Yellow 145 dye, and the composite film also exhibited a better stability and recyclability.

Khan et al. [15] prepared a $\mathrm{TiO}_{2} / \mathrm{GO}$ composite by the liquid phase deposition method; $\mathrm{TiO}_{2}$ nanoparticles deposited on $\mathrm{GO}$ nanosheets (8\%) delivered the highest photocatalytic activity for the degradation of $\mathrm{MB}$ under visible light. Besides chemical methods, $\mathrm{TiO}_{2}-\mathrm{rGO}$ photocatalysts can be prepared by a simple mechanical mixing [16], and the composite displayed a high photocatalytic activity for the decomposition of acetic acid under visible light. 


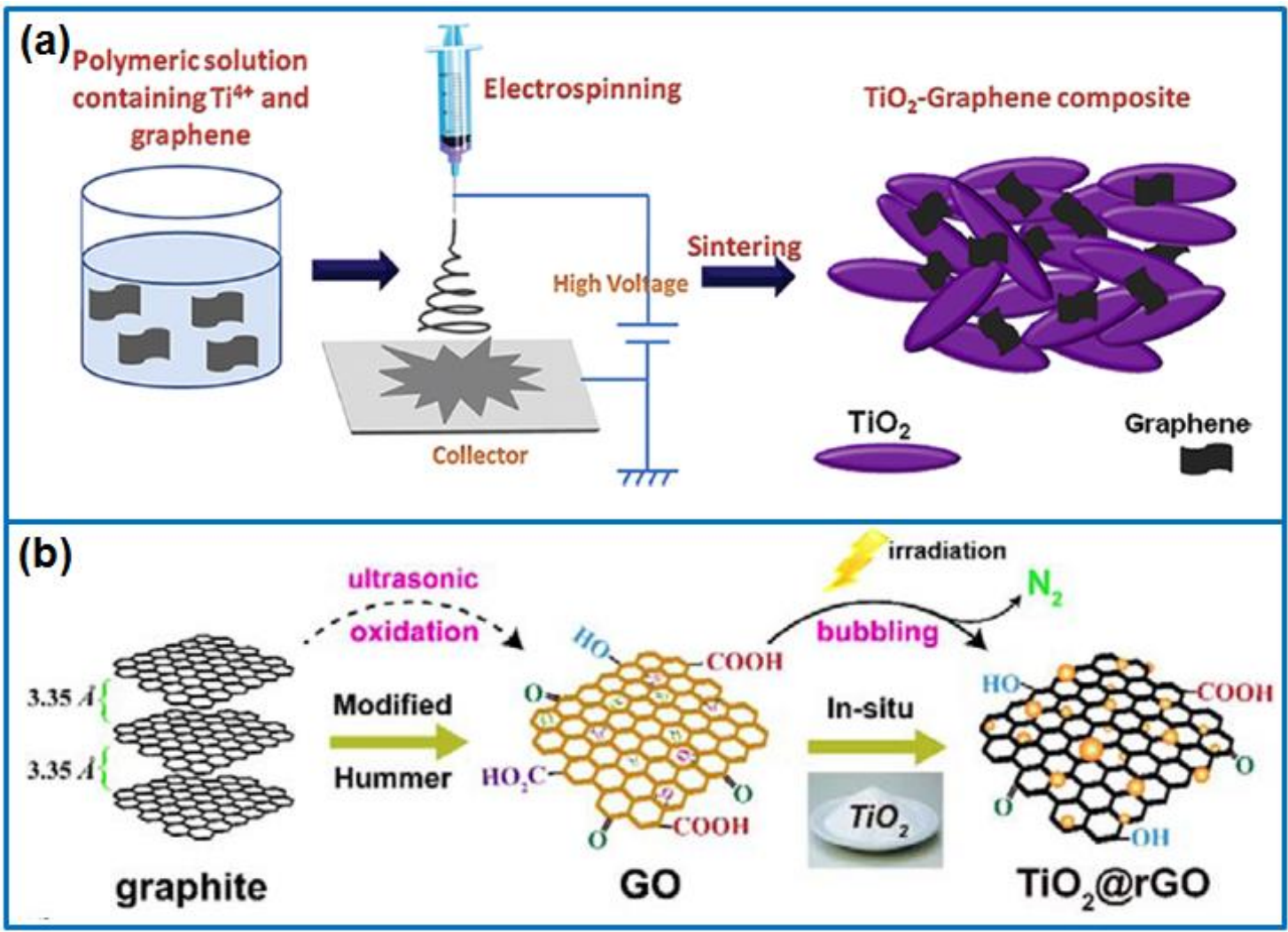

Figure 2. (a) The rice-shaped $\mathrm{TiO}_{2}$-graphene composite prepared by electrospinning; produced with permission [12]. Copyright 2012, American Chemical Society. (b) $\mathrm{TiO}_{2} @ \mathrm{rGO}$ composite prepared by the UV-assisted photoreduction method; produced with permission [13]. Copyright 2017, Elsevier.

\subsubsection{Microstructure Design of $\mathrm{Graphene} / \mathrm{TiO}_{2}$ Composites}

The microstructure of $\mathrm{TiO}_{2}$ or graphene decides the photocatalytic activity. Therefore, various $\mathrm{TiO}_{2}$ nanostructures or modified graphene have been designed to improve the photocatalytic performance. In the microstructure design of $\mathrm{TiO}_{2}$, Yang et al. [17] synthesized various graphene- $\mathrm{TiO}_{2}$ nanocomposites including $\mathrm{TiO}_{2}$ nanoparticles, nanotubes, and nanosheets, and they compared their photoactivity for $\mathrm{CO}_{2}$ reduction and visible-light-induced benzylamine oxidation. The dimensionality of $\mathrm{TiO}_{2}$ affected the interfacial charge transfer and reaction specificity. The graphene- $\mathrm{TiO}_{2}$ nanosheets composite had a higher photocatalytic activity than the composite with $\mathrm{TiO}_{2}$ nanoparticles or nanotubes. Based on the template of polystyrene (PS) microspheres, Yang et al. [18] prepared a porous $\mathrm{TiO}_{2} /$ graphene $^{2}$ composite with an internal surface of rGO layers. The inner layer of graphene suppressed the charge recombination and expanded the light-absorbing capacity, so the composite exhibited an enhanced activity for the degradation of MB.

The feature of graphene also has an important influence on the photocatalytic activity of $\mathrm{TiO}_{2}$ /graphene composites. Trapalis et al. [19] prepared $\mathrm{TiO}_{2} / \mathrm{G}$ and $\mathrm{TiO}_{2} / \mathrm{rGO}$ composites by using pure graphene $(\mathrm{G})$ and $\mathrm{GO}$, respectively. The surfactant-stabilized graphene was confirmed as a zero-band gap conductor, while rGO was a semiconductor with a tunable band gap. Compared to $\mathrm{TiO}_{2} / \mathrm{G}$, the $\mathrm{TiO}_{2} / \mathrm{rGO}$ composite presented a higher De-NOx activity under both UV and visible light. Compared to two-dimensional (2D) graphene nanosheets, graphene quantum dots (GQDs) are a zero-dimensional material with a good solubility, low abundant edge states, and functional groups. Rajender et al. [20] synthesized a $\mathrm{TiO}_{2}-\mathrm{GQD}$ heterojunction by bonding the oxygen vacancy sites in $\mathrm{TiO}_{2}$ with the in-plane epoxy groups in GQDs. The $\mathrm{TiO}_{2}-\mathrm{GQD}$ hybrid expanded the visible light absorption to the near infrared region and facilitated the interfacial charge separation. Therefore, 
the $\mathrm{TiO}_{2}-\mathrm{GQD}$ composite showed an enhanced photodegradation rate (97\%) for the removal of $\mathrm{MB}$ dye under visible light.

In the respect of graphene-wrapped $\mathrm{TiO}_{2}$ nanoparticles, Lee et al. [21] modified anatase $\mathrm{TiO}_{2}$ nanoparticles with a diameter of $500 \mathrm{~nm}$ by using positively charged amine groups; then, they wrapped the $\mathrm{TiO}_{2}$ particles with negatively charged GO nanosheets to fabricate graphene-wrapped $\mathrm{TiO}_{2}$. The wrapped $\mathrm{TiO}_{2}$ displayed a better photocatalytic performance for the degradation of $\mathrm{MB}$ than pure $\mathrm{TiO}_{2}$ and $\mathrm{P} 25$ powder. In another work, hierarchical $\mathrm{TiO}_{2}$ nanoflowers with a high surface area were wrapped by graphene (Figure 3a) [22]. When used for the degradation of MB, graphene-coated flower-like $\mathrm{TiO}_{2}$ increased the dye adsorption capability, induced a red shift in light absorption, and suppressed the recombination of electron-hole pairs. Moreover, graphene-coated hollow $\mathrm{TiO}_{2}$ nanospheres were fabricated by using the template of $\mathrm{SiO}_{2}$ nanospheres [23]. As shown in Figure 3b, the spherical structure exhibited a high degradation rate of $91 \%$ for the removal of $\mathrm{Rh} \mathrm{B}$ in $90 \mathrm{~min}$.

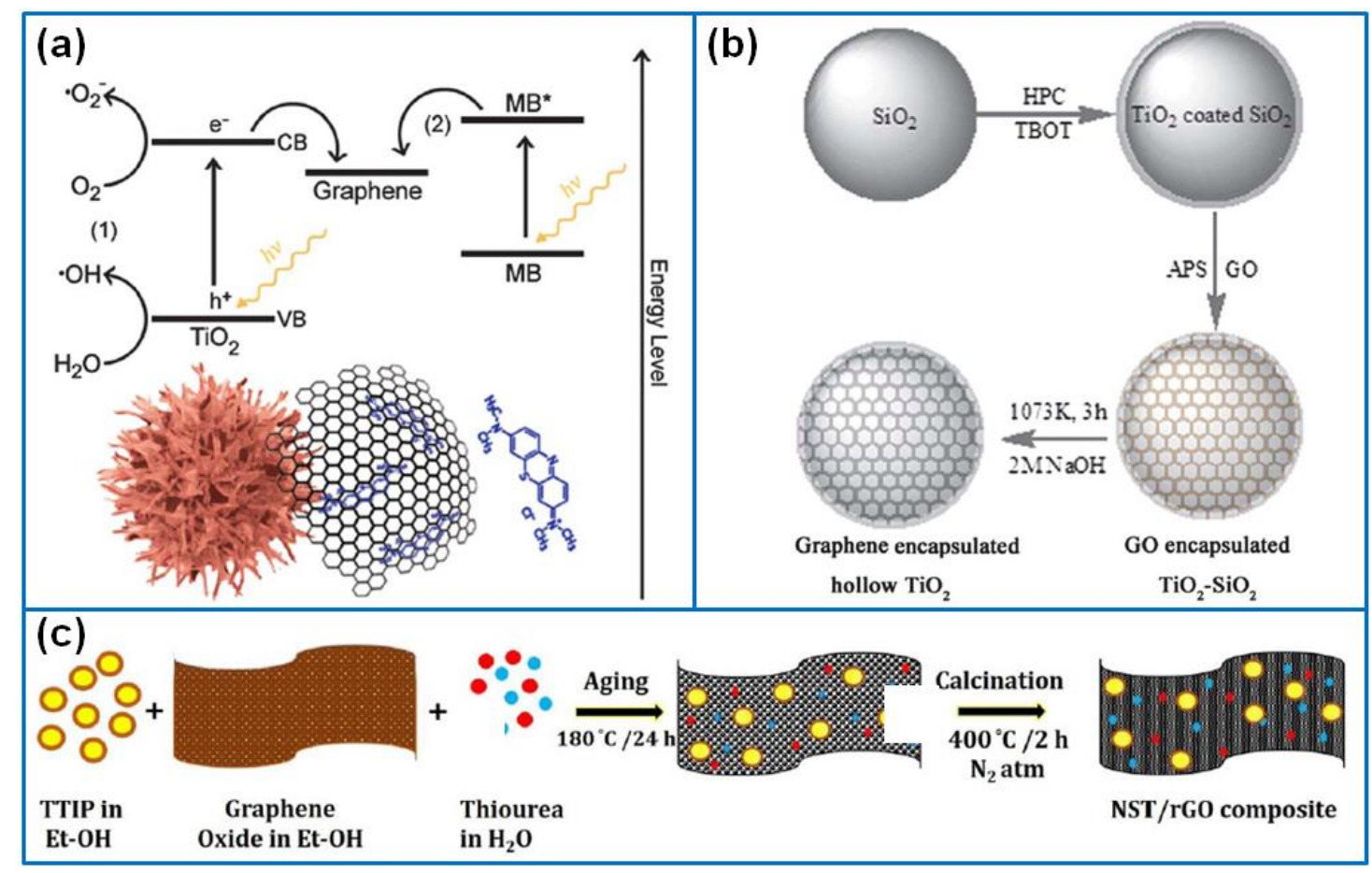

Figure 3. (a) Photocatalytic mechansim of graphene-coated flower-like $\mathrm{TiO}_{2}$; produced with permission [22] Copyright 2013, Royal Society of Chemistry. (b) Graphene-coated hollow $\mathrm{TiO}_{2}$ nanospheres; produced with permission [23]. Copyright 2013, Royal Society of Chemistry. (c) Preparation of N, S co-doped $\mathrm{TiO}_{2}$ composite; produced with permission [24]. Copyright 2017, Elsevier.

\subsubsection{Doping of Graphene or $\mathrm{TiO}_{2}$}

To overcome the limitations of $\mathrm{TiO}_{2}$, such as poor absorption in visible light and fast recombination of electron-hole pairs, non-metal doping $(\mathrm{F}, \mathrm{N}, \mathrm{S}$, and $\mathrm{B})$ and metal doping have been widely reported to improve the photocatalytic activity of $\mathrm{TiO}_{2}$. In the field of non-metal doping, Dai et al. [25] synthesized surface-fluorinated $\mathrm{TiO}_{2}\left(\mathrm{~F}-\mathrm{TiO}_{2}\right)$ nanosheets by hydrothermal reaction, then assembled $\mathrm{F}-\mathrm{TiO}_{2}$ on $\mathrm{GO}$ sheets to fabricate a $\mathrm{GO} / \mathrm{F}-\mathrm{TiO}_{2}$ hybrid photocatalyst. The well exposed (001) facets of the composite presented a higher photocatalytic activity for the degradation of $\mathrm{MB}$ than commercial $\mathrm{P} 25$ and $\mathrm{TiO}_{2}$ nanosheets, which was ascribed to the higher photoelectrochemical current caused by the exposed (001) facet of $\mathrm{F}-\mathrm{TiO}_{2}$ and the interfacial junction between $\mathrm{GO}$ and $\mathrm{F}-\mathrm{TiO}_{2}$. Brindha et al. [24] synthesized $\mathrm{N}$, $\mathrm{S}$ co-doped $\mathrm{TiO}_{2}$, and an rGO matrix simultaneously by using a thiourea precursor via a hydrothermal method, as given in Figure 3c. The N, $\mathrm{S}$ doping reduced the band gap of $\mathrm{TiO}_{2}$, and the non-metal doping on graphene suppressed the recombination of electron-hole pairs. Therefore, the N, S co-doped 
$\mathrm{TiO}_{2} / 5 \%-\mathrm{rGO}$ exhibited the best photocatalytic performance in the degradation of congo red (CR, 93\%), methylene blue (MB, 95\%) and reactive orange 16 (RO16, 96\%). Except for the non-metal doping, metal doping including $\mathrm{Cs}, \mathrm{Cr}, \mathrm{Fe}, \mathrm{Cu}, \mathrm{Ag}$, and $\mathrm{Au}$ has been confirmed to enhance the light adsorption range and the photoactivity of $\mathrm{TiO}_{2}$ in visible light [26]. For instance, Isari et al. [27] prepared Fe-doped $\mathrm{TiO}_{2}$ on $\mathrm{rGO}$ sheets for the decoloration of $\mathrm{Rh} \mathrm{B}$ under solar illumination. The result confirmed that the introduction of Fe ions reduced the band gap of titania. Meanwhile, graphene nanosheets increased the specific surface area of composite and quenched the electron-hole recombination.

\subsubsection{Three-Dimensional (3D) Graphene/ $/ \mathrm{TiO}_{2}$ Composites}

Compared to 2D graphene nanosheets, a 3D graphene network or hydrogel has a continuous structure, with a high mechanical strength, loading ability, and tunable electrical conductivity, which can be easily collected and reused for the removal of organic contaminants. Therefore, 3D porous graphene/metal oxide composites have been designed to improve the photocatalytic activity. In this respect, Zhang et al. [28] prepared an interconnected 3D mesoporous $\mathrm{TiO}_{2}-$ graphene hydrogel (TGH) photocatalyst via a hydrothermal method. Spherical $\mathrm{TiO}_{2}$ nanoparticles decorated on the graphene nanosheets expanded the light absorption range and promoted the charge transportation, which greatly improved the photodegradation efficiency for removing $\mathrm{MB}$ dye. Based on the 3D graphene network (3DGN) deposited on $\mathrm{Ni}$ foam, Zhang et al. [29] deposited $\mathrm{TiO}_{2}-\mathrm{rGO}$ nanosheets on 3DGN by the hydrothermal method. When used for the degradation of phenol, the rGO-3DGN-TiO $\mathrm{T}_{2}$ composite presented a larger decomposition rate constant than that of $\mathrm{rGO}-\mathrm{TiO}_{2}$ and $3 \mathrm{DGN}-\mathrm{TiO}_{2}$, due to the synergy between the 3DGN and rGO nanosheets.

\subsection{Graphene/ZnO Composites}

\subsubsection{Controllable Synthesis of Graphene/ZnO Composites}

Various methods have been adopted to synthesize graphene/ $\mathrm{ZnO}$ composites, such as the solvothermal method, ultrasonic method, chemical precipitation, electrochemical and photochemical method, bio-inspired method, ball milling method, and so on. Atchudan et al. [30] synthesized a ZnO nanoparticles decorated GO ( $\mathrm{ZnO@GO)} \mathrm{composite} \mathrm{by} \mathrm{the} \mathrm{solvothermal} \mathrm{method.} \mathrm{The} \mathrm{introduction}$ of GO enhanced the photocatalytic performance for the degradation of $\mathrm{MB}$, and the degradation efficiency reached $98.5 \%$ in 15 min under UV light. In addition, graphene-coated hierarchical $\mathrm{ZnO}$ was prepared by the solvothermal method [31]. The core-shell structure exhibited a high Rh B removal rate of $98.5 \%$, due to the large specific surface area, enhanced light harvesting range, and fast transfer rate of photogenerated carriers. Adopting ethanol as a solvent, Moussa et al. [32] synthesized small-sized $\mathrm{ZnO}$ rods on $\mathrm{rGO}$ sheets by a solvothermal reaction. The $\mathrm{ZnO} / \mathrm{rGO}$ composite containing $10 \mathrm{wt} \% \mathrm{rGO}$ exhibited the highest photocatalytic activity in the removal of Orange II dye, and the activity almost had no loss after being reused 15 times. In the respect of modified graphene, Zhang et al. [33] synthesized $\mathrm{ZnO}$ particles on aminated graphene (NGO) by a solvothermal reaction. The NGO in the composite effectively extended the photoresponse range and achieved the fast separation of photogenerated carriers. The optimized $\mathrm{ZnO}-\mathrm{NGO}-2$ presented an enhanced degradation activity for the removal of $\mathrm{MO}$ and $\mathrm{MB}$ dye.

Luo et al. [34] synthesized hierarchical ZnO hollow spheres on the rGO sheets by a one-step ultrasonic method. The $\mathrm{ZnO}$ hollow spheres had a large surface area, and the conductive rGO reduced the recombination of electron-hole pairs by providing excellent electron transport. Therefore, the hierarchical rGO-ZnO exhibited enhanced photodegradation efficiency toward MB dye. In another work, an ultrasound-assisted precipitation method was used to synthesize a $\mathrm{ZnO} / \mathrm{GO}$ composite for the degradation of MB [35]. The sonication improved the distribution of particles by reducing the crystallinity of particles. Moreover, the sonication reduced the band gap of ZnO. Víctor-Román et al. [36] synthesized a $\mathrm{ZnO}-\mathrm{GO}$ hybrid by ultrasonic mixing and subsequent freeze-drying for the degradation 
of MB. Through tuning the loading amount and surface chemistry of GO, the optimized composite exhibited a high conversion rate of $80 \%$ in 70 min under UV light.

In addition, the chemical precipitation method can be used to synthesize a graphene-ZnO nanocomposite [37]. The $\mathrm{ZnO}$ nanoparticles $(8-12 \mathrm{~nm}$ ) dispersed on graphene sheets greatly improved the photocatalytic performance. Compared to MB and MO dye, the nanocomposite showed higher removal efficiency for Rh B under visible light. Gayathri et al. [38] also synthesized $\mathrm{ZnO}$ on graphene sheets by the chemical precipitation method. The compoite showed a higher photocatalytic activity in the degradation of $\mathrm{MB}$ than pure $\mathrm{ZnO}$. Jin et al. [39] synthesized $\mathrm{ZnO}$ nanoparticles on the graphene surface by an ionothermal precipitation method. The addition of graphene narrowed the band gap of $\mathrm{ZnO}$, increased the visible light absorption range, and accelerated the separation of photogenerated carriers. Therefore, the $\mathrm{ZnO} /$ graphene nanohybid delivered high photocatalytic efficiency in the degradation of MB.

Reddy et al. [40] fabricated rGO-ZnO nanostructures via a bio-inspired approach, in which the polyamines were used to simultaneously achieve the reduction of $\mathrm{GO}$ and the mineralization of $\mathrm{ZnO}$ nanostructures. The interspersed components in the assembled rGO-ZnO heterostructure enhanced the photocatalytic activity in the decomposition of Rh B under UV light. In addition, the electrochemical method was used to deposit $\mathrm{ZnO}$ nanostructures in GO solution [41], and the GO was reduced simultaneously. Through tuning the $\mathrm{C} / \mathrm{O}$ atomic ratio in $\mathrm{GO}$, the structural defects were formed in $\mathrm{ZnO}$ and GO sheets, which presented a strong interfacial effect and enhanced the photocatalytic activity in the degradation of MB under UV irradiation. Similar to the electrochemical method, a one-step photochemical method was used to synthesize $\mathrm{ZnO}$ nanoparticles on $\mathrm{rGO}$ sheets [42], in which the generation of $\mathrm{ZnO}$ nanoparticles and the reduction of $\mathrm{GO}$ occurred simultaneously. The $\mathrm{ZnO} / \mathrm{rGO}$ nanocomposite delivered improved photocatalytic efficiency toward MB.

Considering the low productivity and abundant liquid waste of solution-based methods, Lonkar et al. [43] prepared graphene-ZnO nanocomposites by ball milling followed by thermal annealing. $\mathrm{ZnO}$ nanoparticles with an average particle size of $9 \mathrm{~nm}$ were uniformly distributed on rGO sheets, which exhibited a larger surface area and a higher photoactivity for the degradation of MB than the composite prepared by the hydrothermal method. Therefore, the mechanothermal process enables a facile and scalable route for fabribating high-performance graphene/metal oxide photocatalysts.

\subsubsection{Microstructure Design of Graphene/ZnO Composites}

In order to improve the photocatalytic activity of graphene/ $\mathrm{ZnO}$ composites, the microstructure design of $\mathrm{ZnO}$ or graphene is a popular strategy. During the synthesis process of $\mathrm{ZnO}$, the surfactant is crucial for deciding the microstructures. Except for the popular surfactant SDS (sodium dodecyl sulfate) or CTAB (hexadecyl trimethyl ammonium bromide), GO can be served as a template to prepare flower-like $\mathrm{ZnO}$ microparticals [44]. Compared to the $\mathrm{ZnO}$ synthesized by using CTAB or amphoteric surfactant BS-12, the flower-like $\mathrm{ZnO}$ microparticles containing GO showed a better photocatalytic activity in the degradation of $\mathrm{Rh} \mathrm{B}$. In another work, Zhao et al. [45] synthesized $\mathrm{ZnO}$ nanoring (NR)-, nanoplate (NP)-, and nanobowl (NB)-decorated rGO composites, respectively. Through a comparison, the $\mathrm{ZnO} \mathrm{NR} / \mathrm{rGO}$ composite (Figure 4a) presented the highest photocatalytic activity in the degradation of Rh B. Qin et al. [31] fabricated a ZnO microspheres-rGO composite by a facile solution method. When used for the photodegradation of $\mathrm{MB}$, the composite exhibited a higher photodegradation activity than that of $\mathrm{ZnO}$ microspheres and commercial P25. Li et al. [46] synthesized flower-like $\mathrm{ZnO}$ nanoparticles on GO sheets by the chemical deposition method. The composite had a hierarchical porosity and large surface area, and it exhibited higher photocatalytic efficiency in the removal of MB, due to the efficient photosensitized electron injection and suppressed charge carriers recombination.

In the respect of controlling the loading of $\mathrm{ZnO}$ on the graphene surface, $\mathrm{Xu}$ et al. [47] discussed the photocatalytic activity of different graphene coverages on the surface of $\mathrm{ZnO}$ nanoparticles. The composite containing $2 \mathrm{wt} \%$ graphene displayed the highest photocatalytic activity in the decomposition of MB. In addition, the $\mathrm{ZnO}$-graphene composite with a multilayer porous network 
structure [48] showed a superior photocatalytic performance for the degradation of MO under visible light, strong adsorption to organic molecules, enhanced separation, and transfer of electron-hole pairs.

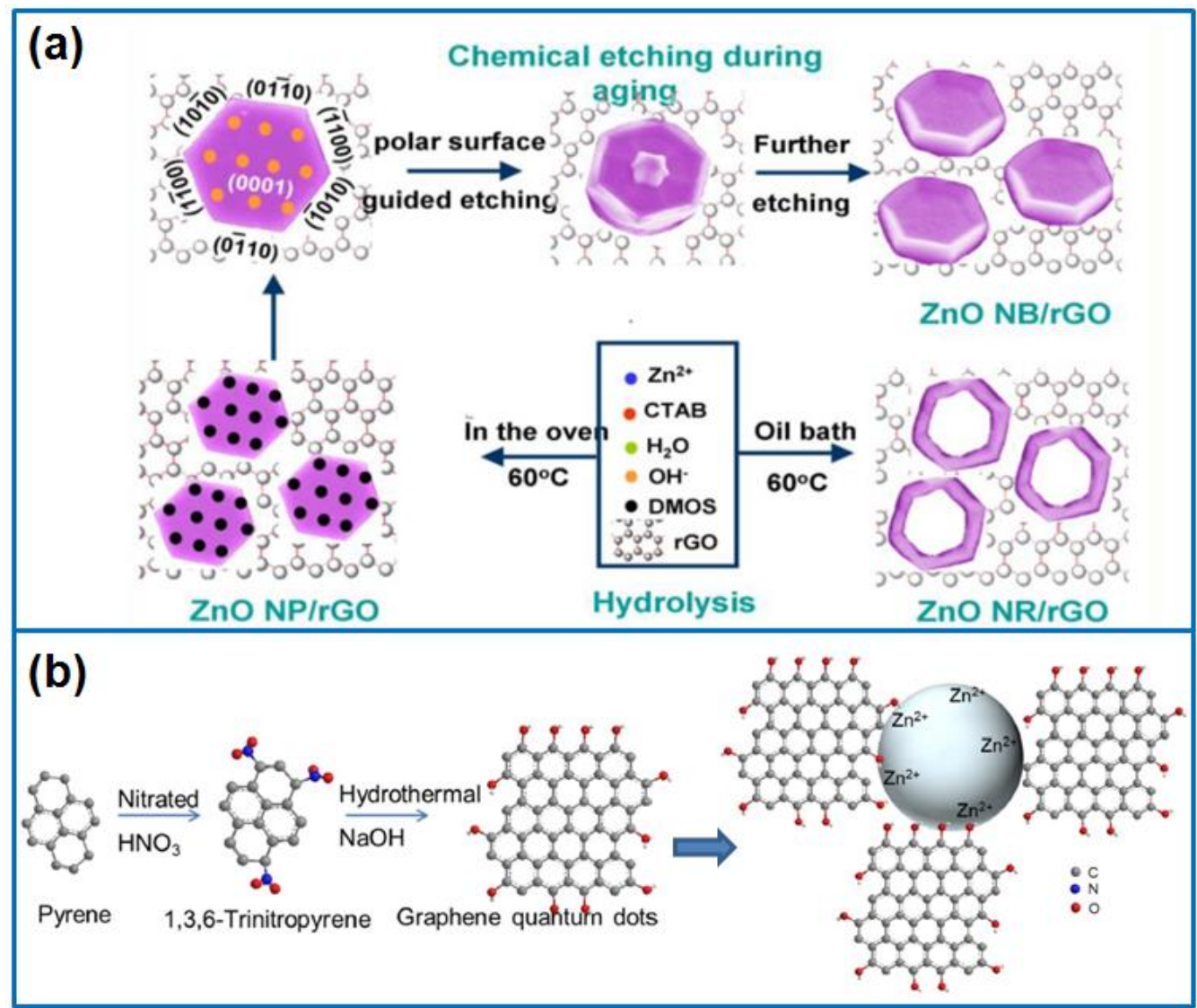

Figure 4. (a) Preparation of $\mathrm{ZnO}$ nanoring on graphene sheets; produced with permission [45]. Copyright 2017, Elsevier. (b) Fabrication of oval-shaped graphene/ZnO quantum hybrid; produced with permission [49]. Copyright 2017, Elsevier.

In the field of graphene quantum dots (GQDs) or ZnO quantum dots (QDs), Van Thuan et al. [49] synthesized an oval-shaped graphene/ZnO quantum hybrid (GZQH) by the chemical-hydrothermal method. As provided in Figure 4b, for GQDs coupled with $\mathrm{ZnO}$ quantum dots with a size of $5 \mathrm{~nm}$, the composite showed a superior photocatalytic performance for the selective reduction of nitroarenes. In addition, the heterojunction of GQD and $\mathrm{ZnO}$ nanorods was developed for the degradation of $\mathrm{MB}$ dye and carbendazim (CZ) [50], and it exhibited a superior photocatalytic activity under sunlight. Thuan et al. [51] disscussed the effect of $\mathrm{ZnO}$ quantum sizes on the photodegradation performance of a $\mathrm{ZnO} / \mathrm{GO}$ hybrid. The result showed that the hybrid of $6 \mathrm{~nm} \mathrm{ZnO/GO}$ exhibited a high photocatalytic activity in the degradation of MB under UV light, which was due to the large surface area and greater amount of surface defects. Tayyebi et al. [52] also synthesized $3 \mathrm{~nm} \mathrm{ZnO} \mathrm{QDs} \mathrm{on} \mathrm{graphene} \mathrm{sheets} \mathrm{by} \mathrm{a}$ simple chemical method. As an ideal substrate, GO hindered the aggregation of ZnO QDs. Meanwhile, graphene effectively adsorbed the MO molecules and separated the electron-hole pairs generated on the surface of $\mathrm{ZnO}$ QDs.

Besides the microstructure control of $\mathrm{ZnO}$, the oxygen vacancy in $\mathrm{ZnO}$ nanocrystals can act as a charge separation center and active sites to mediate the energy transfer between conjugated dyes and $\mathrm{ZnO}$. In view of the importance of the surface oxygen defect, Bai et al. [53] prepared the graphene/ $\mathrm{ZnO}_{1-x}$ composite with a surface oxygen defect by an in situ reduction method. The synergic effect between the $\mathrm{ZnO}_{1-\mathrm{x}}$ surface defect layer and graphene enhanced the separation efficiency of 
electron-hole pairs, which contributed to the superior photocatalytic activity for the degradation of MB under UV and visible light.

\subsubsection{Doping of $\mathrm{ZnO}$}

Ramos-Corona et al. [54] synthesized N-doped $\mathrm{ZnO}$ on GO nanosheets by the microwave-assisted hydrothermal method. Compared to pure $\mathrm{ZnO}$, the $\mathrm{N}$-doped $\mathrm{ZnO} / \mathrm{GO}$ composite showed a higher activity in the degradation of $\mathrm{MB}$ under $\mathrm{UV}$ and visible light. The performance was attributed to the synergistic effect of $\mathrm{GO}$ and $\mathrm{N}$-doped $\mathrm{ZnO}$, which promoted the formation of electron-hole pairs and suppressed their recombination. Besides the non-metal doping, Hsieh et al. [55] synthesized Cu-doped $\mathrm{ZnO}$ on rGO sheets by a microwave-assisted hydrothermal method. The $\mathrm{Cu}$ doping enhanced the visible light response by narrowing the band gap of $\mathrm{ZnO}$, and the conductive rGO effectively confined the recombination of electron-hole pairs. Therefore, the $\mathrm{Cu}$-doped $\mathrm{ZnO} / \mathrm{rGO}$ nanocomposite showed an enhanced activity for the photodegradation of MB dye.

\subsubsection{Free-Standing Graphene/ZnO Composites}

In the field of free-standing graphene/ZnO composites, a 3D hierarchical porous structure provides a fast tranfer pathway for the electron and charge carriers. Meanwhile, the large surface area, mechanical properties, and high conductivity of 3D graphene facilitate the energy conversion. Wang et al. [56] prepared 3D graphene by chemical vapor deposition (CVD); then, they deposited $\mathrm{ZnO}$ nanorods via a hydrothermal method. The 3D G/ZnO composite showed a superior performance in the photodegradation of MO under UV light for the large surface area, as well as a fast separation of electron-hole pairs at the interface of $\mathrm{ZnO}$ and graphene. Men et al. [57] also synthesized $\mathrm{ZnO}$ nanorods arrays on $3 \mathrm{D}$ graphene foam to fabricate a hierarchical $\mathrm{ZnO} / \mathrm{rGO}$ foam. As a photocatalyst, the macroporous graphene scaffold increased the photoelectric response and enhanced the separation efficiency of electron-hole pairs. So, the loading of $\mathrm{ZnO}$ nanorods on 3D graphene enhanced the photocatalytic activity in the degradation of Rh B. Except for the 3D graphene framework composite, a free-standing $\mathrm{GO} / \mathrm{ZnO}$ thin film was developed by depositing $\mathrm{GO}$ sheets on the $\mathrm{ZnO}$ thin film [58]. Under the irradiation of UV light, the UV-treated $\mathrm{GO} / \mathrm{ZnO}$ thin film achieved a complete degradation of $\mathrm{MB}$, due to the reduced the band gap energy and enhanced charge transfer between $\mathrm{ZnO}$ and GO.

\subsection{Graphene/ $/ \mathrm{SnO}_{2}$ Composites}

$\mathrm{SnO}_{2}$ is an $n$-type semiconductor with a band gap width of $3.189 \mathrm{eV}$. Due to its non-toxic nature, low cost, and easy manufacturing, it has been widely used in the field of photocatalysis [59]. However, its wide band gap determines that it mainly absorbs ultraviolet light in sunlight. In order to boost its absorption of visible light, various $\mathrm{SnO}_{2} / \mathrm{GO}$ materials have been designed to enhance the photocatalytic performance.

\subsubsection{Controllable Synthesis of Graphene/ $\mathrm{SnO}_{2}$ Composites}

Among the solution-based chemical methods, a hydrothermal or solvothermal method is the popular way to synthesize graphene/ $\mathrm{SnO}_{2}$ composites. For example, Chen et al. [60] synthesized a hierarchical $\mathrm{SnO}_{2}$ /graphene nanocomposite by a hydrothermal method. The nanocomposites displayed a higher photocatalytic performance for the degradation of $\mathrm{MO}$ dye than pure $\mathrm{SnO}_{2}$. In addition, Chen et al. [61] also synthesized an $\mathrm{SnO}_{2}$ nanorods/graphene composite by using $\mathrm{SnCl}_{4}$ and $\mathrm{GO}$ as raw materials. The $\mathrm{SnO}_{2} / \mathrm{rGO}$ composite showed a high photocatalytic performance for the degradation of $\mathrm{Rh} \mathrm{B}$, due to the synergy effect between the graphene and $\mathrm{SnO}_{2}$ nanorods.

Shyamala et al. [62] synthesized an $\mathrm{rGO}-\mathrm{SnO}_{2}$ composite by a facile chemical method and studied the photocatalytic activity for the degradation of $\mathrm{Rh} B$ under the UV and visible light. The excellent photocatalytic performance of $\mathrm{rGO}-\mathrm{SnO}_{2}$ was ascribed to the extended light absorption in the visible region, as well as its efficient charge separation and transport. In addition, the sol-gel method has been adopted to fabricate $\mathrm{SnO}_{2} / \mathrm{GO}$ nanocomposite (Figure 5a) by dripping Tin (IV) tert-butoxide to GO 
solution [63], and the nanocomposite showed a high activity for the degradation of Rh B under visible light. In another work, Kim et al. [64] synthesized an $\mathrm{SnO}_{2}$ aerogel/rGO nanocomposite via the sol-gel method. The rGO flakes captured in a $3 \mathrm{D} \mathrm{SnO}_{2}$ aerogel matrix reduced the recombination rate of electron-hole pairs. The content of rGO also affected the photocatalytic activity. The composite of $\mathrm{SnO}_{2}$ aerogel/rGO (0.1 wt \%) achieved the MO degradation of $84 \%$ in 60 min under UV light, which was much better than pristine $\mathrm{SnO}_{2}$ aerogel.

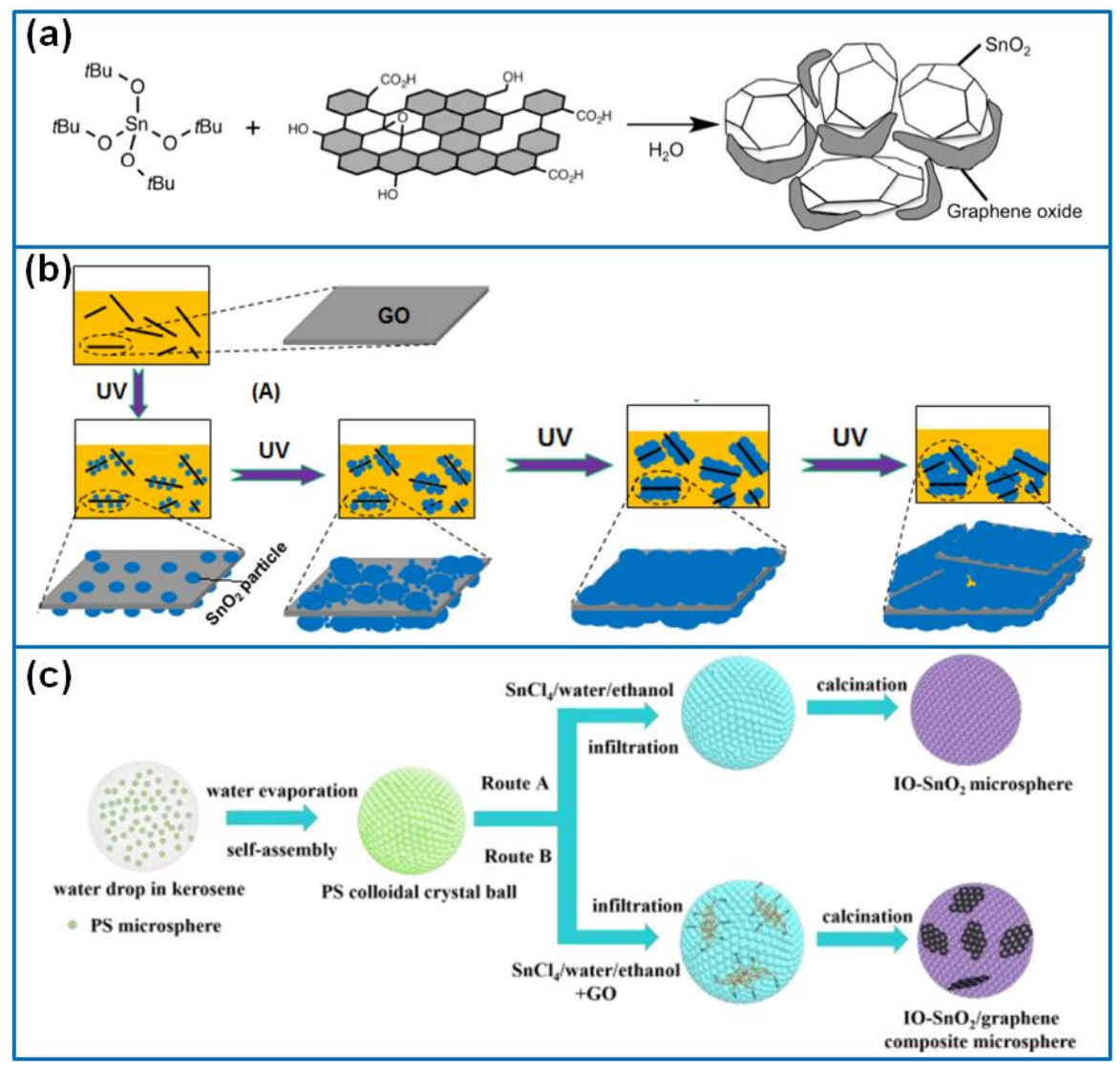

Figure 5. (a) Fabrication of $\mathrm{SnO}_{2} / \mathrm{GO}$ (graphene oxides) nanocomposite by the sol-gel method; produced with permission [63]. Copyright 2018, Elsevier. (b) $\mathrm{SnO}_{2}$ dense layers grown on both sides of reduced graphene oxide (rGO) sheets; produced with permission [65]. Copyright 2017, Elsevier. (c) Preparation of $\mathrm{IOSnO}_{2} / \mathrm{rGO}$ microspheres; produced with permission [66]. Copyright 2015, Royal Society of Chemistry.

In order to save the preparation time, Tang et al. [67] developed a microwave-assisted method to synthesize an $\mathrm{SnO}_{2} / \mathrm{rGO}$ composite. Under the microwave irradiation, the solvent was evaporated rapidly, and $\mathrm{SnO}_{2}$ nanoparticles were formed on the rGO sheets within $10 \mathrm{~min}$. The as-prepared composite displayed a superior photocatalytic activity for the degradation of MB under UV light. Similar to the microwave method, ultraviolet (UV) light irradiation [65] was used to synthesize $\mathrm{SnO}_{2}$ dense layers on both sides of the rGO sheets (Figure $5 \mathrm{~b}$ ) by illuminating the precursor solution containing GO, $\mathrm{SnSO}_{4}$, and $\mathrm{H}_{2} \mathrm{SO}_{4}$. The rGO sheet sandwiched between two $\mathrm{SnO}_{2}$ dense layers enhanced the photoactivity in the degradation of $p$-nitrophenol under sunlight or UV light, and the activity was higher than that of pure $\mathrm{SnO}_{2}$ and other $\mathrm{SnO}_{2}-\mathrm{rGO}$ composites.

Except for the solution-based methods, the $\mathrm{SnO}_{2} /$ graphene composite can be fabricated by a simple solid-phase method [68]. Through grinding the precursors of $\mathrm{SnCl}_{4} \cdot 5 \mathrm{H}_{2} \mathrm{O}$, graphene, PEG-400, and $\mathrm{NaOH}$, the $\mathrm{SnO}_{2}$ nanoparticles were in situ generated on the graphene sheets. $\mathrm{The}_{\mathrm{SnO}} /$ graphene nanocomposite showed an enhanced photocatalytic performance for the removal of $\mathrm{MO}$ and $\mathrm{Rh} \mathrm{B}$, due to the excellent conductivity of graphene and the large specific surface area of composite. 


\subsubsection{Microstructure Design of Graphene/ $\mathrm{SnO}_{2}$ Composites}

In the microstructure design of $\mathrm{SnO}_{2}$ /graphene composites, Xie et al. [69] synthesized $\mathrm{SnO}_{2} /$ graphene quantum dots (GQDs) composite by a simple solution mixing for removing nitric oxide (NO). The combination of small $\mathrm{SnO}_{2}$ nanoparticles (approximately $2.4 \mathrm{~nm}$ ) with GQDs facilitated the charge separation efficiency and improved the visible light response. In addition, Chen et al. [66] prepared 3D inverse opal (IO) $\mathrm{SnO}_{2} / \mathrm{rGO}$ microspheres by using polystyrene (PS) microspheres as templates, as shown in Figure $5 \mathrm{c}$. The special microstructure shifted the light absorption edge more than $400 \mathrm{~nm}$, which effectively suppressed the hole/electron recombination by accelerating the charge carriers transfer. When the GO content was $0.06 \mathrm{wt} \%$, the composite exhibited the best photocatalytic activity for the degradation of $\mathrm{MO}$ dye. In order to investigate the effect of $\mathrm{SnO}_{2}$ microstructures on the photocatalytic degradation of $\mathrm{Rh} \mathrm{B}$, Wei et al. [70] synthesized three kinds of $\mathrm{SnO}_{2}$ microspheres, including dandelion, silkworm cocoon, and urchin shapes on the rGO sheets by a hydrothermal method. Among these composites, the dandelion-like composite exhibited the best photocatalytic performance for the larger specific surface area.

Sephra et al. [71] modified $\mathrm{SnO}_{2}$ microspheres with 3-amino propyl triethoxysilane and wrapped them with GO sheets by the electrostatic self-assembly. After the GO was reduced, the $\mathrm{SnO}_{2} / \mathrm{rGO}$ composite with a ratio of 1:3 achieved the fast degradation of $\mathrm{MB}$ in $3 \mathrm{~min}$ under visible light. In order to disclose the influence of different interface combinations on photocatalytic performance, Shen et al. [72] prepared two kinds of $\mathrm{SnO}_{2} @ \mathrm{rGO}$ core-shell structures through electrostatic interaction (SG-E) and chemical bonding (SG-C), respectively. When evaluated by the photodegradation of MO under UV light, the SG-C composite formed by a chemical bonding interface presented a higher photodegradation rate than the SG-E formed by electrostatic interaction, due to the higher carrier separation efficiency induced by an intimate interface combination between $\mathrm{SnO}_{2}$ and $\mathrm{rGO}$.

As we know, it is so hard to ensure the hydrophilicity of GO after it is thermally reduced. In order to balance the hydrophilicity and conductivity of rGO, our group [73] fabricated a hydrophilic macroporous $\mathrm{SnO}_{2} / \mathrm{rGO}\left(\mathrm{SnO}_{2} / \mathrm{rGO}-\mathrm{HM}\right)$ photocatalyst by using melamine templates. The melamine particles were wrapped with GO sheets decorated with $\mathrm{SnO}_{2}$ nanoparticles to form a core-shell structure. Thermal treatment was conducted to reduce GO, and the wrapped melamine core protected the oxygen-containing groups of the GO inner layer. After being rinsed by hot water, the melamine was removed to form the hydrophilic macroporous structure. The $\mathrm{SnO}_{2} / \mathrm{rGO}-\mathrm{HM}$ exhibited a higher photocatalytic activity for the degradation of Rh B and MB under UV light, which was much better than the ordinary $\mathrm{SnO}_{2} / \mathrm{rGO}$ composite and commercial P25.

\subsubsection{Doping of $\mathrm{SnO}_{2}$}

Metal doping of $\mathrm{SnO}_{2}$ is a promising strategy to improve the photoresponse to visible light. Othmen et al. [74] hybridized Fe-doped $\mathrm{SnO}_{2}$ nanoparticles with rGO through a three-step method. The Fe-doped $\mathrm{SnO}_{2} / \mathrm{rGO}$ nanocomposite achieve a high degradation rate of $93 \%$ for removing $\mathrm{Rh} \mathrm{B}$ dye in $80 \mathrm{~min}$. The enhanced performance was caused by the synergistic effect of Fe doping and rGO hybridization, in which the Fe-doping of $\mathrm{SnO}_{2}$ ensured the generation of electron-hole pairs under visible light irradiation, and the rGO facilitated the charge separation by trapping the excited electrons.

\subsection{Graphene/ $\mathrm{WO}_{3}$ Composites}

As an important $n$-type semiconductor, $\mathrm{WO}_{3}$ has a band gap of $2.8 \mathrm{eV}$, which has been widely used in the photocatalysis field for the physicochemical stability and strong absorption in the visible light range [75]. Recently, various $\mathrm{WO}_{3}$ /graphene composites have been developed as high-performance visible light photocatalysts. Tie et al. [76] synthesized $\mathrm{WO}_{3}$ nanorods on $\mathrm{rGO}$ sheets by a solvothermal method. When used for the degradation of methylthionine chloride, the optimized composite achieved a degradation efficiency of more than $94.1 \%$ within 150 min under visible light, due to the reduced recombination of photogenerated charges caused by the well-defined $\mathrm{WO}_{3}-\mathrm{rGO}$ interface. 
In addition, $\mathrm{Fu}$ et al. [77] synthesized a $\mathrm{WO}_{3}-\mathrm{rGO}$ nanocomposite by a one-pot hydrothermal method. The nanocomposite showed high activity in the degradation of MB for the facilitated electron transport, expanded light absorption, and excellent conductivity of rGO sheets. By using a hydrothermal method, Gan et al. [78] synthesized $\mathrm{WO}_{3}$ nano-sticks on graphene sheets, and the composite displayed higher degradation efficiency to $\mathrm{MB}$ dye under visible light. Khan et al. [79] synthesized $\mathrm{WO}_{3}$ nanorods on graphene nanosheets for photodegradation of the MB under visible light. Khan et al. [80] also synthesized an indigo-rGO/ $\mathrm{WO}_{3}$ nanocomposite by a hydrothermal method. The indigo dye and graphene overcome the low photocatalytic activity of $\mathrm{WO}_{3}$ caused by its lower mobility and fast combination of electron and hole pairs. Moreover, the indigo dye in $\mathrm{rGO} / \mathrm{WO}_{3}$ served as the reaction site for promoting the charge transfer efficiency. Therefore, the indigo-rGO/ $\mathrm{WO}_{3}$ composite exhibited a superior photocatalytic activity for the degradation of $\mathrm{MB}$ at the $\mathrm{pH}$ of 11.0 under sunlight.

Besides the hydrothermal method, Ismail et al. [81] synthesized a mesoporous $\mathrm{WO}_{3}-\mathrm{GO}$ nanocomposite by the sol-gel method and then deposited Pt nanoparticles to fabricate $\mathrm{Pt} / \mathrm{WO}_{3}-\mathrm{GO}$ nanocomposites for the photocatalytic degradation of MB dye. The enhanced photocatalytic performance resulted from the freedom electron transfer between $\mathrm{WO}_{3}$ and $\mathrm{GO}$ sheets. Meanwhile, $\mathrm{Pt}$ nanoparticles suppressed the electron-hole pair recombination by serving as active sites for $\mathrm{O}_{2}$ reduction. Zhou et al. [82] synthesized a $\mathrm{WO}_{3}$ nanorods@graphene composite by a photoreduction method, in which a Xenon lamp was used to illuminate the mixture of $\mathrm{WO}_{3}$ nanorods and GO in solution to reduce the GO. The composite presented a higher photocatalytic activity for the degradation of $\mathrm{MO}$ than pure $\mathrm{WO}_{3}$ nanorods. In addition, Huang et al. [83] synthesized a high-ordered mesoporous $\mathrm{WO}_{3}\left(\mathrm{~m}-\mathrm{WO}_{3}\right) / \mathrm{rGO}$ composite by a UV-assisted reduction method. The optimized photocatalyst containing $6 \mathrm{wt} \%$ rGO exhibited an enhanced performance for oxygen evolution under visible light, which was about 5.1 times higher than that of $\mathrm{m}-\mathrm{WO}_{3}$.

Jeevitha et al. [84] prepared a $\mathrm{WO}_{3}-\mathrm{GO}$ nanocomposite by an ultrasonication method, and the $\mathrm{WO}_{3}-\mathrm{GO}$ nanocomposite exhibited enhanced degradation efficiency for removing methylene blue (MB) and indigo carmine (IC) under visible light. Guo et al. [85] synthesized $\mathrm{WO}_{3}$ nanoparticles on the graphene surface by a sonochemical method. The optimized $\mathrm{WO}_{3} @$ graphene composite displayed an excellent photocatalytic property for water splitting due to the synergistic effect of graphene sheets and $\mathrm{WO}_{3}$ nanoparticles.

As a kind of particle deposition technique, a nanoparticle deposition system (NPDS) can be used to fabricate thin films on different substrates [86]. Therefore, NPDS was used to fabricate a few-layer graphene $/ \mathrm{WO}_{3}$ thin film for the degradation of $\mathrm{MB}$ dye [87]. The composite film containing $15 \mathrm{wt} \%$ of graphite exhibited the best photocatalytic performance for the degradation of MB dye in $2 \mathrm{~h}$, and the film photocatalyst also showed a superior photostability and durability during recycling.

\subsection{Graphene $/ \mathrm{Fe}_{2} \mathrm{O}_{3}$ Composite}

$\mathrm{Fe}_{2} \mathrm{O}_{3}$ is an $n$-type semiconductor with an indirect band gap of approximately $2.1-2.2 \mathrm{eV}$, which has been widely utilized as a photocatalyst, due to its properties of easy recovery, environmentally friendliness, high stability, and low cost [88]. In order to suppress the recombination of photogenerated electron and hole pairs and enhance the photocatalytic activity of single $\mathrm{Fe}_{2} \mathrm{O}_{3}$, the hybridization of graphene with $\mathrm{Fe}_{2} \mathrm{O}_{3}$ has been attempted to improve the photocatalytic efficiency. In this field, various $\mathrm{Fe}_{2} \mathrm{O}_{3}$ nanostructures are generated on the graphene surface by hydrothermal reaction or other physical methods. In addition, the $\mathrm{N}$-doped graphene or noble metal particles-decorated graphene have been reported to enhance the photocatalytic activity of graphene/ $/ \mathrm{Fe}_{2} \mathrm{O}_{3}$ composites.

Pradhan et al. [89] prepared an $\alpha-\mathrm{Fe}_{2} \mathrm{O}_{3}$ nanorod/rGO composite via a hydrothermal method. The composite photocatalyst containing $5 \mathrm{wt} \%$ rGO presented 4 times enhancement in the photocatalytic activity for the degradation of phenol under solar radiation. The high performance was ascribed to the high utilization of photoelectron, the low recombination of electron and hole pairs, and the fast production of active $\mathrm{OH}$ radical. In addition, hexagonal $\alpha-\mathrm{Fe}_{2} \mathrm{O}_{3}$ nanoplates/graphene was synthesized by a hydrothermal method [90]. The $\alpha-\mathrm{Fe}_{2} \mathrm{O}_{3}$ nanoplates were uniformly dispersed on 
graphene, which facilitated the charge transfer from $\alpha-\mathrm{Fe}_{2} \mathrm{O}_{3}$ to graphene. The composite with $5 \mathrm{wt} \%$ graphene achieved the fast degradation of $\mathrm{Rh} \mathrm{B}$ in $20 \mathrm{~min}$, which was much faster than that of pure $\alpha-\mathrm{Fe}_{2} \mathrm{O}_{3}$. Kumar et al. [91] also synthesized an $\mathrm{Fe}_{2} \mathrm{O}_{3} / \mathrm{rGO}$ nanocomposite by a hydrothermal method and utilized them for the degradation of 4-nitrophenol (4-NP) under visible light. Zheng et al. [92] prepared a $\gamma-\mathrm{Fe}_{2} \mathrm{O}_{3} /$ graphene composite by a bubbling-assisted exfoliating method, and the composite delivered a superior photocatalytic activity for the degradation of MO with an excellent recyclable degradation performance.

In the field of modified graphene, Wang [93] synthesized a magnetic $\mathrm{N}$-doped graphene/ $\mathrm{Fe}_{2} \mathrm{O}_{3}$ composite (MNG) via a hydrothermal reaction with a dopant of ethylenediamine. When used for the degradation of $\mathrm{MB}$, the MNG containing $50 \% \mathrm{Fe}_{2} \mathrm{O}_{3}$ presented the best photocatalytic performance and a high recycled decolorization rate of $85.4 \%$ after three recycles. In addition, the composite could be easily collected by using an external magnet. The $\mathrm{N}$-doped graphene- $\mathrm{Fe}_{2} \mathrm{O}_{3}$ composite can be used as a photocatalyst for $\mathrm{CO}_{2}$ reduction and acetaldehyde degradation [94]. The results showed that the coupling of $\mathrm{N}$-doped graphene with $\mathrm{Fe}_{2} \mathrm{O}_{3}$, especially for the doped quaternary- $\mathrm{N}$, played a major role in promoting the transfer and transportation of photogenerated charges, while the doped pyridinic-N and pyrrolic-N almost had no contribution to the photocatalytic activity.

\subsection{Graphene/ $\mathrm{C} u_{2} \mathrm{O}$ Composite}

As a $p$-type semiconductor, $\mathrm{Cu}_{2} \mathrm{O}$ has a band gap of $2.0 \mathrm{eV}$, which has been widely used for the degradation of organic contaminants or water splitting [95]. However, the single crystal of $\mathrm{Cu}_{2} \mathrm{O}$ exhibits low energy conversion efficiency for the rapid recombination of the photogenerated electrons and holes. To overcome the shortage of $\mathrm{Cu}_{2} \mathrm{O}$, graphene has been coupled with $\mathrm{Cu}_{2} \mathrm{O}$ to inhibit the recombination of electron-hole pairs. Following this strategy, Wang et al. [96] synthesized spherical $\mathrm{Cu}_{2} \mathrm{O}$ particles $(200 \mathrm{~nm}$ ) on the graphene sheets by reducing the copper acetate adsorbed GO precursors with ethylene glycol reductant. The $\mathrm{Cu}_{2} \mathrm{O} / \mathrm{rGO}$ nanocomposite delivered a superior photocatalytic activity for the degradation of $\mathrm{Rh} B$ dye, which was due to the increased reaction sites and enhanced specific surface area. Zhang et al. [97] prepared cubic $\mathrm{Cu}_{2} \mathrm{O}$ nanoparticles-decorated $\mathrm{rGO}$ sheets by reducing the $\mathrm{GO}$ adsorbed with $\mathrm{Cu}^{2+}$ by using a glucose reductant. The introduction of rGO enhanced the adsorption capacity of UV-Vis light and increased the separation efficiency of the carrier. When utilized for the degradation of methylthionine chloride, the composite showed 1.6 times higher photocatalytic activity than that of pure $\mathrm{Cu}_{2} \mathrm{O}$. In addition, Liu et al. [98] prepared $\mathrm{Cu}_{2} \mathrm{O} / \mathrm{rGO}-\mathrm{x}$ composites with different amounts of $\mathrm{GO}$ by using ascorbic acid as a reducing agent. The smaller $\mathrm{Cu}_{2} \mathrm{O}$ nanoparticles $(10.3 \mathrm{~nm})$ on the graphene surface presented an enhanced photocatalytic activity for the degradation of ulfamethoxazole and MB under visible light, which was due to the enhanced separation and transfer of photogenerated carriers.

\subsection{Graphene/Other Metal Oxide Composites}

Except for the above widely reported metal oxides, graphene has been coupled with other $n$-type semiconductors including $\mathrm{V}_{2} \mathrm{O}_{5}$ [99], $\mathrm{CeO}_{2}, \mathrm{Nb}_{2} \mathrm{O}_{5}, \mathrm{NiO}, \mathrm{Co}_{3} \mathrm{O}_{4}, \mathrm{MoO}_{3}$, and $\mathrm{In}_{2} \mathrm{O}_{3}$ to improve the photocatalytic activity. Shanmugam et al. [100] prepared an $\mathrm{rGO} / \mathrm{V}_{2} \mathrm{O}_{5}$ nanocomposite via a simple solution mixing (Figure 6a). $\mathrm{V}_{2} \mathrm{O}_{5}$-rods decorated graphene nanosheets exhibited a higher activity for the degradation of $\mathrm{MB}$ dye than that of pure $\mathrm{V}_{2} \mathrm{O}_{5}$ rods, which was due to the presence of conducting graphene medium. Aawani et al. [101] synthesized an $\mathrm{rGO}-\mathrm{V}_{2} \mathrm{O}_{5}$ nanocomposite by hydrothermally treating $\mathrm{V}_{2} \mathrm{O}_{5}$ nanorods and $\mathrm{rGO}$ suspension. The introduction of graphene reduced the band gap of the nanocomposite to $1.60 \mathrm{eV}$ from $2.26 \mathrm{eV}\left(\mathrm{V}_{2} \mathrm{O}_{5}\right)$, which enhanced the charge separation and improved the photocatalytic activity of the nanocomposite. Compared to visible light and UV light, the illumination of a mercury lamp had the maximum photodegradation efficiency of $85 \%$ for the decolorization of MB solution in $255 \mathrm{~min}$.

Huang et al. [102] synthesized well-dispersed $\mathrm{CeO}_{2}$ nanocubes (NCs) on the $\mathrm{rGO}$ nanosheets via a hydrothermal method. The $\mathrm{rGO} / \mathrm{CeO}_{2} \mathrm{NCs}$ composite presented a superior performance in 
the photodegradation of MB under UV light, which was much better than the pure $\mathrm{CeO}_{2} \mathrm{NCs}$ and $\mathrm{rGO} / \mathrm{CeO}_{2}$ nanowires composite, due to the effective inhibition of the recombination of photogenerated electron-hole pairs. Based on the $\mathrm{Nb}_{2} \mathrm{O}_{5}$ nanofibers prepared by the electrospinning technique, Qi et al. [103] prepared graphene nanocluster-decorated $\mathrm{Nb}_{2} \mathrm{O}_{5}$ nanofibers by using glucose as carbon precursors. The graphene layers modified the band gaps of $\mathrm{Nb}_{2} \mathrm{O}_{5}$ clusters, so the graphene-decorated $\mathrm{Nb}_{2} \mathrm{O}_{5}$ nanofibers ( $\mathrm{G} @ \mathrm{Nb}_{2} \mathrm{O}_{5} \mathrm{NFs}$ ) showed an enhanced photocatalytic activity for the degradation of MO under visible light. In addition, Ahmad et al. [104] discussed the photocatalytic activity of $\mathrm{NiO} / \mathrm{GO}$ nanocomposites for the degradation of MB solution. The heterojunction formed between $p$-type $\mathrm{NiO}$ and $n$-type GO enhanced the separation efficiency of photogenerated electrons and holes, and the composite containning 65\% GO presented the highest degradation rate of $97 \%$ in 50 min under $500 \mathrm{~W}$ mercury light, which was much higher than that of cubic NiO.

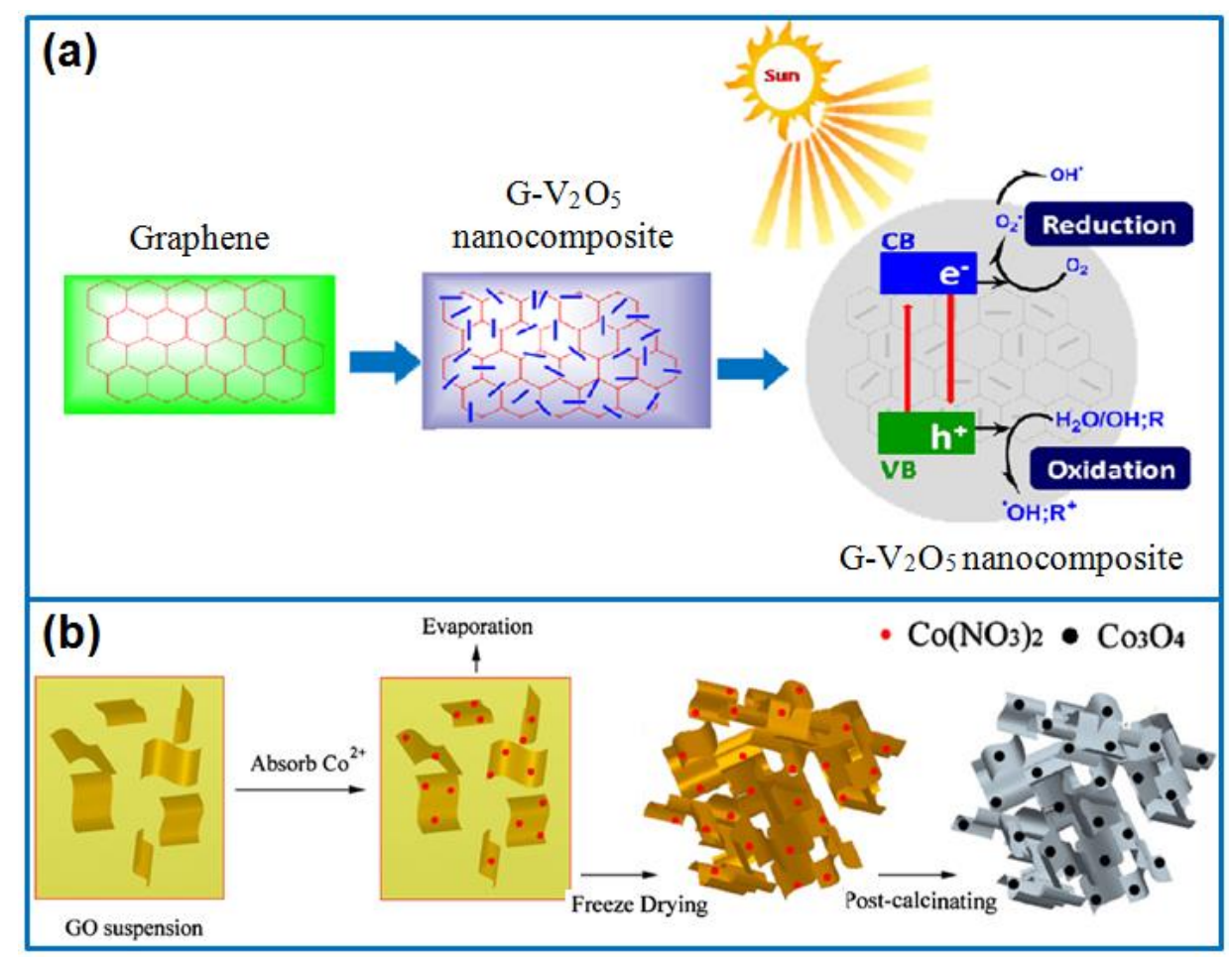

Figure 6. (a) The $\mathrm{rGO} / \mathrm{V}_{2} \mathrm{O}_{5}$ nanocomposite and its photocatalytic mechanism; produced with permission [100]. Copyright 2015, American Chemical Society. (b) Preparation of 3D porous graphene- $\mathrm{Co}_{3} \mathrm{O}_{4}$ nanocomposites; produced with permission [105]. Copyright 2015, Elsevier.

Compared to 2D graphene-based composites, 3D porous graphene exhibits some advantages, such as abundant porosity, interconnected electron transport pathway, strong adsorption, easy to recycle, and so on. Considering the magnetic decantation feature of $\mathrm{Co}_{3} \mathrm{O}_{4}$, Bin et al. [105] synthesized 3D porous graphene- $\mathrm{Co}_{3} \mathrm{O}_{4}\left(\mathrm{Co}_{3} \mathrm{O}_{4}-\mathrm{G}\right.$, Figure $\left.6 \mathrm{~b}\right)$ nanocomposites via freeze-drying and a calcination method. The $\mathrm{Co}_{3} \mathrm{O}_{4}-\mathrm{G}$ photocatalyst delivered an excellent photocatalytic performance for removing $\mathrm{MO}$ under visible light, due to the enhanced transfer of photogenerated charges, and strong adsorption of dye molecules. In addition, the catalyst can be easily collected from the solution by magnetic decantation.

As a narrow band gap semiconductor, $\alpha-\mathrm{MoO}_{3}$ has a superior feature of light absorption; it can be used for photocatalysis and solar energy-related fields. Ramar et al. [106] prepared rGO-wrapped $\alpha-\mathrm{MoO}_{3}$ nanoplates for the degradation of $\mathrm{MB}$ under the solar light. The rGO layers on $\mathrm{MoO}_{3}$ nanoplates inhibited the electron-hole recombination, which enhanced the photocatalytic activity of the composite. Therefore, $\mathrm{rGO}$-wrapped $\mathrm{MoO}_{3}$ presented a much higher photocatalytic activity than that of pure $\mathrm{MoO}_{3}$. Ding et al. [107] synthesized a mesoporous $\mathrm{In}_{2} \mathrm{O}_{3} / \mathrm{rGO}$ composite by UV-assisted photoreduction. The continuouly porous channels reduced the transfer path of photogenerated carriers, 
and the highly conductive rGO suppressed the recombination of electron-hole pairs. The resultant composite containing ca. $2 \%$ rGO achieved a high photodegradation rate of $96 \%$ for the degradation of 4-chlorophenol under visible light.

In this section, we summarize the research progress of graphene/metal oxide binary composites, including graphene $/ \mathrm{TiO}$, graphene $/ \mathrm{ZnO}$, graphene $/ \mathrm{SnO}_{2}$, graphene $/ \mathrm{WO}_{3}$, graphene $/ \mathrm{Fe}_{2} \mathrm{O}_{3}$, graphene $/ \mathrm{Cu}_{2} \mathrm{O}$, and other metal oxides. As provided in Table S1 to Table S6, in view of the difference of dye type, concentration, the usage of catalyst, and light source, it is hard to evaluate the photocatalytic activity of the same graphene/metal oxide composite. However, the combination of graphene with metal oxides greatly improves the photocatalytic efficiency of individual metal oxide. Among the existing works, the controllable synthesis and microstructure design are the basic research ideas. Lots of chemical methods are reported to synthesize graphene/metal oxide composites, including hydrothermal or solvothermal methods, the sol-gel method, photochemical/electrochemical methods, the ultrasonic method, chemical precipitation, liquid phase deposition, the bio-inspired method, and so on. In addition, some physical methods including physical mixing, ball milling, and nanoparticle deposition system (NPDS) have been used for preparing graphene/metal oxide composites. The microstructure of metal oxides or graphene has an important influence on the photocatalytic performance of composites. For instance, the nanorings, quantum dots, mesoporous structure, hirarchical nanoflowers, hollow spheres, and 3D porous framework have been developed and present an excellent photodegradation performance for the large surface area, more active sites, and strong interfacial binding. In addition, the heteroatom doping of metal oxide or graphene is a practical strategy for enhancing the photocatalytic efficiency. In this field, F-doped $\mathrm{TiO}_{2}, \mathrm{~N}, \mathrm{~S}$ co-doped $\mathrm{TiO}_{2}, \mathrm{Fe}$-doped $\mathrm{TiO}_{2}, \mathrm{~N}$-doped $\mathrm{ZnO}, \mathrm{Cu}$-doped $\mathrm{ZnO}$, Fe-doped $\mathrm{SnO}_{2}$, and $\mathrm{N}$-doped graphene have been reported to enhance the visible light response by narrowing the band gap of metal oxides. In order to develop high-performance photocatalysts, the graphene has coupled with novel metal oxides, including $\mathrm{V}_{2} \mathrm{O}_{5}, \mathrm{CeO}_{2}, \mathrm{Nb}_{2} \mathrm{O}_{5}, \mathrm{NiO}, \mathrm{Co}_{3} \mathrm{O}_{4}, \mathrm{MoO}_{3}$, and $\operatorname{In}_{2} \mathrm{O}_{3}$. These novel binary composites present an excellent photocatalytic activity, as well as traditional graphene $/ \mathrm{TiO}_{2}$, graphene/ $\mathrm{ZnO}$, and graphene $/ \mathrm{SnO}_{2}$ composites.

\section{Graphene/Metal Oxide Ternary Composites}

In order to expand the light absorption range, promote the interfacial charge transfer, and inhibit the recombination of photogenerated electron-hole pairs, graphene/metal oxide ternary composites often show obvious advantages over the binary composites for the synergistic effect of multi-components. However, the selection of the components, the microstructure design, and the optimization of ratios decide the photocatalytic performance of ternary composites. In the design of graphene-based ternary composites, the researchers attempt to hybridize two kinds of metal oxides to form various heterojunctions. Different from metal oxides, metal nanoparticles often serve as electron-trapping sites in the photocatalysis process to enhance interfacial charge transfer [108]. Therefore, the other promising strategy is loading metal nanoparticles and metal oxide onto the graphene sheets. For example, the introduction of noble metal nanoparticles, including $\mathrm{Au}, \mathrm{Ag}, \mathrm{Pd}$, and $\mathrm{Pt}$ onto the surface of graphene/metal oxide would expand the light absorption range, thus greatly enhancing the photocatalytic activity of composites. In this section, we specifically summarize the research progress of graphene/metal oxide ternary composite photocatalysts, including graphene/ $/ \mathrm{TiO}_{2^{-}}$, graphene/ZnO-, graphene $/ \mathrm{SnO}_{2-}$, graphene $/ \mathrm{Cu}_{2} \mathrm{O}_{-}$, graphene $/ \mathrm{Fe}_{\mathrm{x}} \mathrm{O}_{\mathrm{y}^{-}}$, and graphene/Bi- containing ternary composites.

\subsection{Graphene/TiO ${ }_{2}$-Based Ternary Composites}

In the ternary composite photocatalysts, graphene often serves as a conductive substrate to support metal nanoparticles or metal oxides. Furthermore, the formation of a heterojunction on graphene efficiently accelerates the interfacial charge transfer and suppresses the recombination of electron-hole pairs. Among the existing graphene/ $\mathrm{TiO}_{2}$-based ternary composites, the third component can be selected from metal nanoparticles, $\mathrm{WO}_{3}, \mathrm{ZnO}, \mathrm{Cu}_{2} \mathrm{O}, \mathrm{Fe}_{2} \mathrm{O}_{3}, \mathrm{BiVO}_{4}$, and so on. 


\subsubsection{Graphene/ $\mathrm{TiO}_{2} /$ Metal Nanoparticles}

In view of the special funtion of metal nanoparticles in the photocatalysis field, such as enhancing the interfacial charge transfer and expanding the light absorption range, various noble metal nanoparticles including $\mathrm{Au}, \mathrm{Ag}, \mathrm{Pd}$, and $\mathrm{Pt}$ have been hybridized with graphene/ $\mathrm{TiO}_{2}$ to improve the photocatalytic activity of composites. In this field, Safajou et al. [109] prepared a Pd nanoparticles $/ \mathrm{rGO} / \mathrm{TiO}_{2}$ photocatalyst by hydrothermal and photodeposition. In this ternary composite, $\mathrm{Pd}$ nanoparticles collected the photogenerated electrons, and conductive graphene provided a fast transfer path for charge carriers or electrons. Compared to the $\mathrm{rGO} / \mathrm{TiO}_{2}$ composite, the ternary composite exhibited a higher activity in the degradation of $\mathrm{Rh} \mathrm{B}$, with a better recycling stability. Zhao et al. [110] prepared an $\mathrm{Ag} / \mathrm{TiO}_{2} / \mathrm{rGO}$ ternary nanocomposite by a combined sol-gel/solvothermal method for photodegrading MB dye. In this composite, Ag nanoparticles expanded the light absorption of the $\mathrm{TiO}_{2}$, and the rGO conductor promoted the electron-hole separation by inhibiting the charge recombination. In another work, Leong et al. [111] synthesized Ag-wrapped $\mathrm{TiO}_{2}$ on $\mathrm{rGO}$ sheets to form an $\mathrm{rGO}-\mathrm{Ag} / \mathrm{TiO}_{2}$ ternary composite. When used for the degradation of Bisphenol A, this ternary composite delivered much better photocatalytic activity than pure $\mathrm{TiO}_{2}, \mathrm{Ag} / \mathrm{TiO}_{2}$, and $\mathrm{rGO}-\mathrm{TiO}_{2}$. The reason can be attributed to the synergized effect of $\mathrm{Ag}$ and $\mathrm{rGO}$. Uniformly dispersed $\mathrm{Ag}$ nanoparticles expanded the light absorption range, while the rGO sheets triggered visible light shift toward the red spectrum and accelerated the transfer of photogenerated electrons. In addition, Ghasemi et al. [112] confirmed that the decoration of Au nanoparticles on $\mathrm{TiO}_{2}$-graphene increased the visible light absorption range, while the Au nanoparticles and graphene impeded the charge recombination of photoexcited $\mathrm{TiO}_{2}$. As a result, the $\mathrm{Au} @ \mathrm{TiO}_{2}-\mathrm{rGO}$ nanocomposite displayed a superior photocatalytic performance for the degradation of Acid Blue 92 under visible and UV light.

\subsubsection{Graphene $/ \mathrm{TiO}_{2} / \mathrm{WO}_{3}$ Composite}

$\mathrm{WO}_{3}$ has a superior photocatalytic activity under visible light, and the heterojunction of $\mathrm{TiO}_{2} / \mathrm{WO}_{3}$ (TW) has been synthesized and presented a higher photocatalytic activity than that of pure $\mathrm{TiO}_{2}$ [94] or $\mathrm{WO}_{3}$ [113]. In order to improve the interficial interaction between $\mathrm{TiO}_{2}$ and $\mathrm{WO}_{3}$, Zeng et al. [114] prepared a Z-scheme heterojunction photocatalyst $\mathrm{TiO}_{2} / \mathrm{rGO} / \mathrm{WO}_{3}$ (TRW) by depositing $\mathrm{TiO}_{2}$ nanocrystals and $\mathrm{WO}_{3}$ nanorods onto an $\mathrm{rGO}$ substrate (Figure 7a). Serving as an electron mediator in the Z-scheme transfer process, $\mathrm{rGO}$ not only effectively confines the recombination of electron-hole pairs, but also accelerates the electron transfer and the $\mathrm{O}_{2}$ reduction reactions. Therefore, the ternary composite presented an enhanced bacterial inactivation performance compared with that of the $\mathrm{TiO}_{2} / \mathrm{WO}_{3}$ composite.

In addition, Zhang et al. [115] synthesized spherical $\mathrm{TiO}_{2}$ and $\mathrm{WO}_{3}$ nanoparticles on $\mathrm{rGO}$ sheets by a salt ultrasonic-assisted hydrothermal method. Through adjusting the ratio of three components, the optimized $\mathrm{TiO}_{2} / \mathrm{WO}_{3} / \mathrm{rGO}$ ternary nanocomposite (nTi:nW:nG $=1: 1: 4$ ) had a largest specific surface area of $144.59 \mathrm{~m}^{2} \mathrm{~g}^{-1}$, which presented the highest photocatalytic activity for the degradation of $\mathrm{Rh} \mathrm{B}$. He et al. [116] prepared a graphene-modified $\mathrm{WO}_{3} / \mathrm{TiO}_{2}$ step-scheme (S-scheme) heterojunction via a one-step hydrothermal method (Figure $7 \mathrm{~b}$ ). In this ternary composite, an S-scheme heterostructure was formed between the $\mathrm{TiO}_{2}$ and $\mathrm{WO}_{3}$ nanoparticles, and a Schottky junction was formed between the rGO sheets and $\mathrm{TiO}_{2}$, which accelerated the charge transfer and separation by a strong interfacial interaction and inhibited the recombination of electrons and holes. Therefore, this ternary composite exhibited an enhanced performance for photocatalytic $\mathrm{H}_{2}$ evolution. 


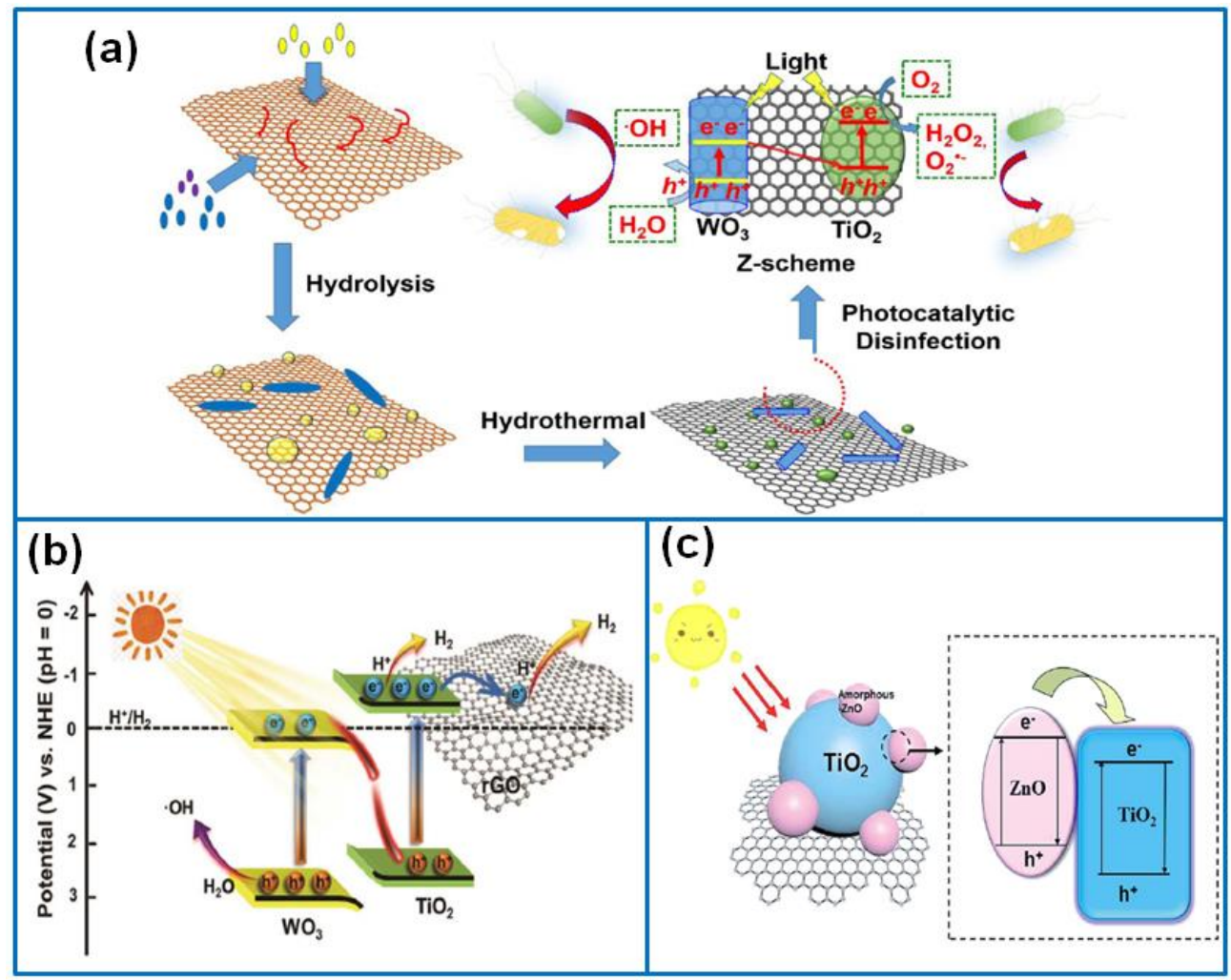

Figure 7. (a) Preparation of $\mathrm{TiO}_{2} / \mathrm{rGO} / \mathrm{WO}_{3}$ photocatalyst; produced with permission [114]. Copyright 2017, Elsevier. (b) Graphene-modified $\mathrm{WO}_{3} / \mathrm{TiO}_{2}$ step-scheme heterojunction; produced with permission [116].

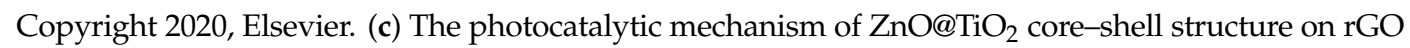
sheets; produced with permission [117].

Besides controlling the microstructure of metal oxides, metal doping is more efficient to further improve the photocatalytic performance of $\mathrm{TiO}_{2} / \mathrm{WO}_{3}$. Iliev et al. [118] prepared an Au-doped $\mathrm{WO}_{3} / \mathrm{TiO}_{2} / \mathrm{rGO}$ composite via the sol-gel method and then compared the photocatalytic activity for the oxidation of 2,4-dichlorophenoxyacetic acid (2,4-D) with corresponding binary or ternary composites. The rGO sheets and Au nanoparticles simultaneously promoted the charge carrier separation, so the $\mathrm{Au} / \mathrm{WO}_{3} / \mathrm{TiO}_{2} / \mathrm{rGO}$ composite presented a maximum photooxidation rate constant. The rate constant value was reduced in the following order: $\mathrm{Au} / \mathrm{WO}_{3} / \mathrm{TiO}_{2} / \mathrm{rGO}>\mathrm{Au} / \mathrm{TiO}_{2} / \mathrm{rGO}>\mathrm{Au} / \mathrm{WO}_{3} / \mathrm{TiO}_{2}>$ $\mathrm{WO}_{3} / \mathrm{TiO}_{2} / \mathrm{rGO}>\mathrm{Au} / \mathrm{TiO}_{2}>\mathrm{TiO}_{2} / \mathrm{rGO}>\mathrm{WO}_{3} / \mathrm{TiO}_{2}$. From the order of activity, the Au-doping of $\mathrm{WO}_{3} / \mathrm{TiO}_{2}$ even displays a higher photocatalytic activity than that of $\mathrm{WO}_{3} / \mathrm{TiO}_{2} / \mathrm{rGO}$.

\subsubsection{Graphene/ $\mathrm{TiO}_{2} /$ Other Metal Oxides}

Considering the high surface area of porous structure, the combination of amorphous phase $\mathrm{ZnO}$ with anatase phase $\mathrm{TiO}_{2}$ will produce much more catalytic centers, which effectively improves the photocatalytic performance. Following this principle, Guo et al. [117] synthesized a microporous amorphous $\mathrm{ZnO} @ \mathrm{TiO}_{2}$ core-shell structure (Figure 7c) on the rGO sheets for the first time. This ternary composite had a high surface area of $336 \mathrm{~m}^{2} \mathrm{~g}^{-1}$, and it exhibited a superior photocatalytic activity and stability for the degradation of $\mathrm{Rh} \mathrm{B}$ and $\mathrm{MB}$ under a simulated solar light. Except for introducing amorphous $\mathrm{ZnO}$, the porous hypercrosslinked polymer (HCP) can be in situ knitted on $\mathrm{TiO}_{2}$-functionalized graphene $\left(\mathrm{TiO}_{2}-\mathrm{FG}\right)$ to achieve the combination of microporous polymers with inorganic photocatalyst [119]. The novel $\mathrm{HCP}-\mathrm{TiO}_{2}-\mathrm{FG}$ composite had a high surface area of $988 \mathrm{~m}^{2} \mathrm{~g}^{-1}$, which greatly enhanced the adsorption and diffusion of $\mathrm{CO}_{2}$ molecules. Therefore, the composite showed an improved photocatalytic activity for the conversion of $\mathrm{CO}_{2}$ to $\mathrm{CH}_{4}$, due to the fast photogenerated charge separation and wide visible-light absorption range caused by graphene and 
HCP layers. Except for coupling with polymer, carbon nanotubes (CNTs) can be adopted to enhance the photocatalytic activity of the $\mathrm{TiO}_{2} / \mathrm{rGO}$ composite. Huang et al. [120] fabricated a $\mathrm{TiO}_{2} /$ carbon nanotubes (CNTs)/rGO ternary composite by a one-pot solvethermal method. Through optimizing the ratio of the three components, the $\mathrm{TiO}_{2} / \mathrm{CNTs} / \mathrm{rGO}-3 \%$ composite presented an outstanding photocatalytic activity for the degradation of $\mathrm{Rh} \mathrm{B}$.

In addition, Nanakkal et al. [121] developed an $\mathrm{rGO} / \mathrm{BiVO}_{4} / \mathrm{TiO}_{2}(\mathrm{GBT})$ ternary nanocomposite via an ultrasonic-assisted one-pot hydrothermal method. Through tuning the band gap of the $\mathrm{BiVO}_{4}$ and $\mathrm{TiO}_{2}$ by changing the concentrations of $\mathrm{GO}$ and $\mathrm{TiO}_{2}$, the optimized GBT nanocomposite achieved the complete degradation of $\mathrm{MB}$ in 10 min under visible light, which was much faster than $\mathrm{rGO} / \mathrm{BiVO}_{4}(40 \mathrm{~min})$, due to the introduction of a GO electron trapper and $\mathrm{TiO}_{2}$-mediating co-catalyst in the composite.

In view of the poor recycling and collection of the powder photocatalysts, carbon cloth can be served as a flexible conductive substrate to prepare self-supporting photocatalysts. For instance, Huang et al. [122] synthesized $\mathrm{TiO}_{2}$ nanosheet arrays (NSAs) and rGO on carbon fiber firstly; then, they deposited $\mathrm{Cu}_{2} \mathrm{O}$ to fabricate $\mathrm{TiO}_{2} \mathrm{NSAs} / \mathrm{rGO} / \mathrm{Cu}_{2} \mathrm{O}$ composite. The $p$-type semiconductor $\mathrm{Cu}_{2} \mathrm{O}$ expanded the light absorption range, and rGO promoted charge transfer efficiency; thus, the composite grown on carbon cloth exhibited an outstanding performance for the degradation of RhB. Meanwhile, the flexible self-supporting property of composite faciliated the collection and recycling.

\subsection{Graphene/ZnO-Based Ternary Composites}

\subsubsection{Metal Doping or Introducing Metal Nanoparticles}

As a semiconductor photocatalyst, $\mathrm{ZnO}$ has some advantages, including its wide band gap, non-toxic nature, and high photosensitivity. However, the fast recombination of photogenerated electron-hole pairs deteriorates the photocatalytic performance of $\mathrm{ZnO}$ [123]. In the graphene/ZnO-based composites, conductive graphene effectively suppresses the recombination of electron-hole pairs by tranferring the photogenrated electrons. Similar to graphene, noble metal doping or loading metal nanoparticles also inhibits the recombination of electron-hole pairs and expands the visible light absorption. Ahmad et al. [124] deposited Ag-doped ZnO nanoparticles on the rGO sheets by a one-step solvothermal method. The composite delivered a higher photocatalytic activity in the degradation of $\mathrm{Rh} B, \mathrm{MB}$, and $\mathrm{MO}$ dyes, which was much better than that of $\mathrm{Ag}$-doped $\mathrm{ZnO}$ and pure $\mathrm{ZnO}$. The superior activity of the ternary composite resulted from the enhanced visible light absorption, strong adsorption of dyes, the fast electron transfer, and the retarded charge recombination rate. Besides single atom-doped $\mathrm{ZnO}$, Zhu et al. [125] prepared Fe and $\mathrm{Cu}$ co-doped $\mathrm{ZnO} / \mathrm{GO}$ photocatalysts by the sol-gel method. The $\mathrm{Fe}-\mathrm{Cu}-\mathrm{ZnO} / \mathrm{GO}$ composite effectively degraded dark green dye under visible light, and the degradation rate was much faster than $\mathrm{ZnO} / \mathrm{GO}$ and $\mathrm{Cu}-\mathrm{ZnO} / \mathrm{GO}$ photocatalysts for the narrow band gap, stronger light absorption, and the fast charge separation capability.

Kheirabadi et al. [126] prepared a free-standing Ag nanoparticles/ZnO nanorods/3D graphene network $(\mathrm{Ag} / \mathrm{ZnO} / 3 \mathrm{DG})$ composite for the degradation of $\mathrm{MB}$ dye. In this ternary composite, $\mathrm{Ag}$ nanoparticles were generated on $\mathrm{ZnO}$ nanorods, which increased the photocatalytic efficiency for the electron capturing properties. The 3DG network had a high conductivity, which played an important role in accelerating the transfer of the photogenerated electron, adsorbing the organic dyes and allowing the fast separation and recovery. In addition, Mu et al. [127] deposited Au nanoparticles on graphene-coated 3D Ni foam and then synthesized various $\mathrm{ZnO}$ nanostructures on Ni/graphene/Au by a hydrothermal method. Through a comparison, the graphene/Au/ZnO nanoplates coated on $\mathrm{Ni}$ foam exhibited a superior photocatalytic performance for the degradation of MO. In this multi-component composite, Au nanoparticles expanded the UV light absorption, and the Schottky heterojunction between $\mathrm{Au}$ and $\mathrm{ZnO}$ reduced the band gap, promoted the electron transfer, and inhibited the recombination of electron-hole pairs. 
Besides the free-standing 3D graphene matrix, the composite film photocatalysts can be fabricated on different substrates by a spin-coating method. Followed this strategy, Li et al. [128] prepared a novel heterostructure photocatalyst of graphene quantum dots (GQDs)-modified $\mathrm{ZnO}+\mathrm{Cu}$ composite by spin-coating and annealing. The composite film showed an enhanced photocatalytic activity for degrading $\mathrm{Rh} \mathrm{B}$, which was due to the wide light absorption range, fast charge separation, and transfer that resulted from the synergistic effects of GQDs and Cu nanoparticles.

\subsubsection{Fabrication of Heterojunction}

In order to improve the photocatalytic efficiency of metal oxides, the fabrication of the heterojunction is a practical strategy that can be achieved by introducing other semiconductors into graphene/ZnO composites. In this field, Wang et al. [129] prepared a $\mathrm{TiO}_{2}$ nanorod arrays (NRAs)/graphene/ZnO nanoparticles ternary composite for enhancing the degradation rate of MB. The graphene sheets effectively transported the photoexcited electrons generated from $\mathrm{TiO}_{2}$ and $\mathrm{ZnO}$. The ternary composite exhibited an improved photocatalytic activity under visible light, which was 2.6 times higher than that of the $\mathrm{TiO}_{2} / \mathrm{ZnO}$ heterostructure.

To overcome the low yield of chemical synthesis, Lonkar et al. [130] prepared $\mathrm{ZnS}-\mathrm{ZnO} / g r a p h e n e$ heterostructured photocatalysts by ball milling of $\mathrm{GO}, \mathrm{Zn}$, salt, and sulfur powder, followed by thermal annealing, as given in Figure 8a. The $\mathrm{ZnS}-\mathrm{ZnO}$ heterostructure decorated on graphene sheets greatly reduced the recombination rate of photogenerated charge carriers, which presented a significant photocatalytic activity in the degradation of $\mathrm{MB}, \mathrm{MO}$, and toxic nitrophenols under visible light. In the microstructure design of $\mathrm{ZnO}$, Yu et al. [131] fabricated $\mathrm{ZnO}$ dumbbells as templates to prepare a hollow dumbbell-like ZnO@ZnS/graphene composite. As shown in Figure 8b, the heterostructure of $\mathrm{ZnO@ZnS} \mathrm{provided} \mathrm{a} \mathrm{new} \mathrm{transfer} \mathrm{pathway} \mathrm{of} \mathrm{electrons} \mathrm{from} \mathrm{ZnS}$ to graphene. Therefore, the ternary composite showed a better photocatalytic activity for the degradation of $\mathrm{MO}$ than that of $\mathrm{ZnO} @ \mathrm{ZnS}$ hollow dumbbells and pure $\mathrm{ZnO}$. In addition, the hollow structure also enhanced the adsorption and diffusion of gas molecules, so the composite also presented a superior selectivity and sensitivity when serving as an alcohol gas sensor.

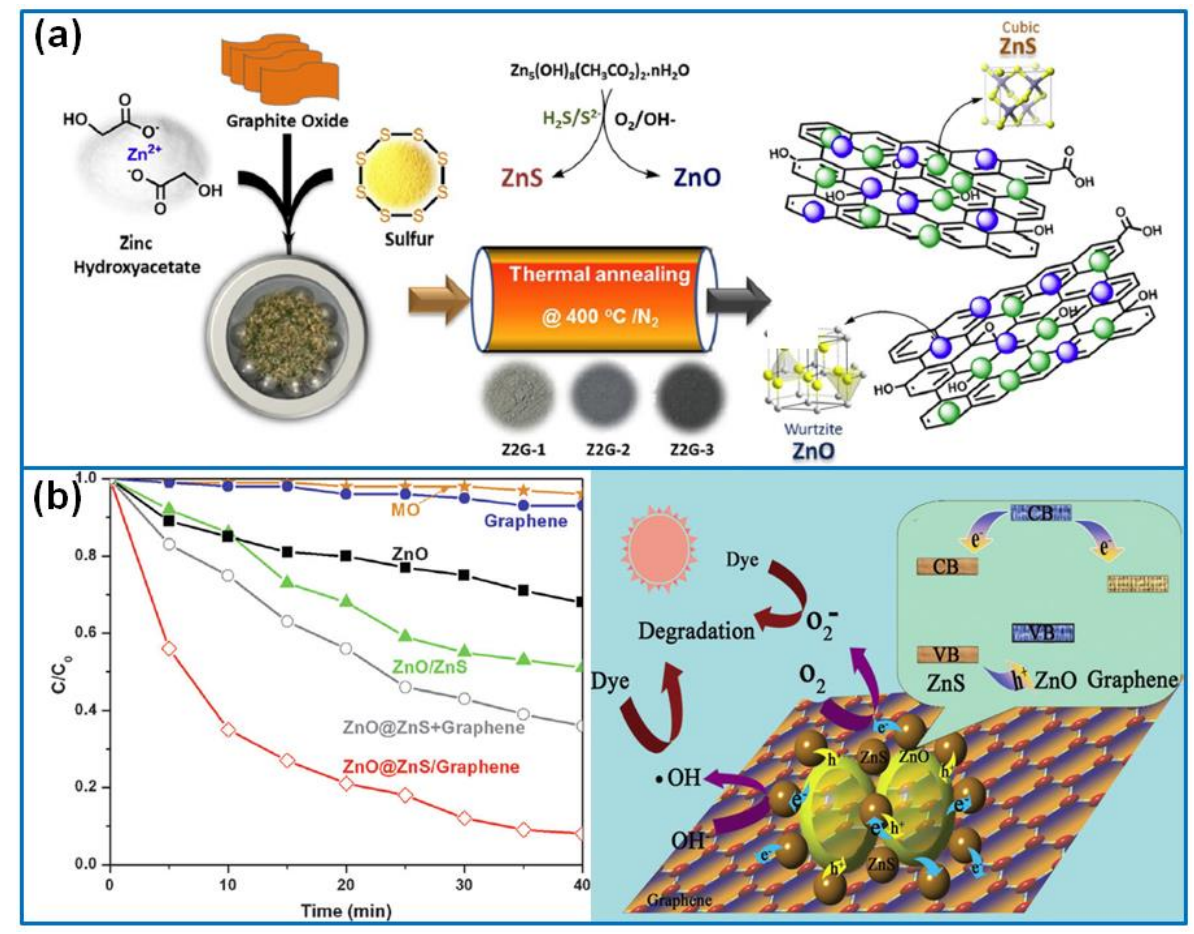

Figure 8. (a) Preparation of $\mathrm{ZnS}-\mathrm{ZnO} /$ graphene heterostructured photocatalysts by ball milling; produced with permission [130]. (b) The performance of ZnO@ZnS/graphene composite and its photocatalytic mechanism; produced with permission [131]. Copyright 2012, Royal Society of Chemistry. 
Shandilya et al. [132] synthesized an $\mathrm{Eu}^{3+}$-doped $\mathrm{ZnO} / \mathrm{Bi}_{2} \mathrm{O}_{3}$ heterojunction on the $\mathrm{GO}$ surface for the degradation of 2, 4-dimethyl phenol (DMP). $\mathrm{Eu}^{3+}$-doped $\mathrm{ZnO}$ reduced the band gap of $\mathrm{ZnO}$, and the integration of $\mathrm{Eu}^{3+}$-doped $\mathrm{ZnO}$ with $\mathrm{Bi}_{2} \mathrm{O}_{3}$ extended the light absorption toward the visible region. Therefore, the $\mathrm{Eu}^{3+}$-doped heterojunction delivered a higher photocatalytic activity than that of the $\mathrm{ZnO} / \mathrm{Bi}_{2} \mathrm{O}_{3} / \mathrm{GO}$ composite. Zhang et al. [133] prepared a $\mathrm{ZnO} / \mathrm{CoFe}_{2} \mathrm{O}_{4} /$ graphene ternary composite by a co-precipitation method and hydrothermal method. The composite showed a superior photocatalytic activity for the degradation of MB dye. Meanwhile, the composite had a good water dispersibility, convenient magnetic separation, and highly repeatable degradability.

\subsection{Graphene/SnO $\mathrm{O}_{2}$-Based Ternary Composites}

$\mathrm{SnO}_{2}$ is a kind of $n$-type semiconductor. Due to the easy fabrication, low cost, and environmental compatibility, it has been widely used for photocatalysis, gas sensors, supercapacitors, and rechargeable batteries [134]. In order to further enhance the photocatalytic activity of the graphene/ $\mathrm{SnO}_{2}$ composite, the introduction of metal nanoparticles, other metal oxides, or sulfides has been reported in recent years.

Mohanta et al. [135] prepared an $\mathrm{Au}-\mathrm{SnO}_{2}-\mathrm{rGO}$ ternary hetrojunction photocatalyst for the degradation of clothianidin. The ternary composite achieved a degradation rate of about $97 \%$ in $120 \mathrm{~min}$ under the UV-LED (light emitting diode) irradiation, due to the synergistic effect of the heterojunction. In this composite, the surface plasmon resonance (SPR) effect of Au nanoparticles extended the light-harvesting range, and the rGO reduced the recombination of charge or carriers. Wang et al. [136] prepared a $\mathrm{Cu}_{2} \mathrm{O} / \mathrm{SnO}_{2} /$ graphene (CSG) composite by a sol-gel method. The combination of graphene with semiconductors expanded the light absorption range and facilitated the transfer of photoinduced electrons and holes between $\mathrm{SnO}_{2}$ and $\mathrm{Cu}_{2} \mathrm{O}$. Meanwhile, the loading of $\mathrm{Cu}_{2} \mathrm{O}$ enhanced the photoelectric activity. Therefore, the CSG delivered a better photodegradability to pendimethalin than $\mathrm{SnO}_{2} /$ graphene and pure $\mathrm{SnO}_{2}$.

In view of the excellent photocatalytic activity of $\mathrm{Zn}_{2} \mathrm{SnO}_{4}$, Li et al. [137] synthesized a $\mathrm{SnO}_{2}-\mathrm{Zn}_{2} \mathrm{SnO}_{4} /$ graphene $\mathrm{Z}$-scheme photocatalyst by a one-pot hydrothermal method. The graphene improved the visible light photocatalytic activity by introducing $\mathrm{Sn}$ vacancy in $\mathrm{SnO}_{2}$; it also transferred the photogenerated electrons from $\mathrm{Zn}_{2} \mathrm{SnO}_{4}$ and inhibited the recombination of carriers. Therefore, the ternary composite containing $3.0 \mathrm{wt} \%$ graphene exhibited the best photocatalytic activity for the degradation of acetone and NO. Huang et al. [138] synthesized $\mathrm{SnS}_{2}-\mathrm{SnO}_{2}$ heterojunctions on graphene sheets by a two-step hydrothermal method. When used for the photodegradation of Rh B, the decolorization rate of $97.1 \%$ can be reached within 60 min under visible light, which is much better than pure $\mathrm{SnO}_{2}$ and the $\mathrm{SnS}_{2}-\mathrm{SnO}_{2}$ heterojunction. The superior photocatalytic performance was attributed to its high surface area, enhanced visible light absorption, and fast separation of electrons and holes.

\subsection{Graphene/Cu $u_{2} \mathrm{O}$-Based Ternary Composites}

In order to improve the photoactivity of $p$-type $\mathrm{Cu}_{2} \mathrm{O}, \mathrm{In}_{2} \mathrm{O}_{3}$ can be used to hybridize with $\mathrm{Cu}_{2} \mathrm{O}$ for forming a $p-n$ heterojunction. For instance, Liu et al. [139] prepared a corn-shaped $\mathrm{Cu}_{2} \mathrm{O} / \mathrm{rGO} / \mathrm{In}_{2} \mathrm{O}_{3}$ hybrid with abundant oxygen vacancies. The oxygen vacancies and heterojunction formed between $\mathrm{In}_{2} \mathrm{O}_{3}$ and $\mathrm{Cu}_{2} \mathrm{O}$ reduced the band gap of the hybrid, and the generated built-in electric field between $p$-type $\mathrm{Cu}_{2} \mathrm{O}$ and $n$-type $\operatorname{In}_{2} \mathrm{O}_{3}$ confined the recombination of photogenerated electron-hole pairs. As a result, the ternary composite showed a higher photocatalytic performance for the degradation of MB.

\subsection{Graphene/Fe $e_{x} O_{y}$-Based Ternary Composites}

Among those different Fe-containing oxides, $\mathrm{Fe}_{2} \mathrm{O}_{3}$ and $\mathrm{Fe}_{3} \mathrm{O}_{4}$ have been widely used for semiconductor photocatalysts. Yan et al. [140] developed a Pt-decorated $\mathrm{GO} / \mathrm{Fe}_{2} \mathrm{O}_{3}$ nanosheet (Pt/GOFe) composite for the room-temperature oxidation of formaldehyde. In this composite, GO nanosheets optimized the surface property of $\mathrm{Pt} / \mathrm{Fe}$, and the hydroxyls in $\mathrm{GO}$ anchored $\mathrm{Pt}$ nanoparticles. $\mathrm{The} \mathrm{Fe}_{2} \mathrm{O}_{3}$ 
nanoplates conductivity partly reduced the GO, and the oxygen species in the GO contributed to the outstanding catalytic activity for indoor air purification.

Considering the high saturation magnetization of $\mathrm{Fe}_{3} \mathrm{O}_{4}$, graphene $/ \mathrm{Fe}_{3} \mathrm{O}_{4}$-based composites can be magnetically separated from suspension, which is beneficial for the repeatable application of powder-like photocatalysts. Boruah et al. [141] synthesized a magnetically recoverable composite of $\mathrm{Fe}_{3} \mathrm{O}_{4} @ \mathrm{~V}_{2} \mathrm{O}_{5} / \mathrm{rGO}$ by a solution chemistry method. The combination of $\mathrm{Fe}_{3} \mathrm{O}_{4}$ and $\mathrm{V}_{2} \mathrm{O}_{5}$ adjusted the band gap, confined the rapid recombination of electron-hole pairs, and facilitated the transfer of photogenerated charge. Moreover, the conductive rGO also accelerated the transfer of photogenerated electrons. Therefore, the ternary composite delivered a superior photocatalytic activity for the degradation of Acid Orange 7 and Bismarck Brown under sunlight irradiation.

\subsection{Graphene/Bi-Containing Ternary Composites}

As the special metal oxide semiconductors, Bi-containing compounds including $\mathrm{BiVO}_{4}$ and $\mathrm{BiOX}$ also have an excellent photocatalytic activity for the degradation of organic pollutants. $\mathrm{BiVO}_{4}$ has a narrow band gap of $2.4 \mathrm{eV}$; when utilized for visible-light photocatalysis, the weak surface adsorption, poor conductivity, and migration rate of electron-hole pairs limit its application in photocatalysis [142]. Therefore, $\mathrm{BiVO}_{4}$ has been coupled with graphene and other semiconductors to improve its photocatalytic properties. For example, Zhang et al. [143] fabricated a Z-scheme g- $\mathrm{C}_{3} \mathrm{~N}_{4} / \mathrm{rGO} / \mathrm{BiVO}_{4}$ nanocomposite through electrostatic adsorption, as well as hydrothermal and thermal oxidation. In this ternary composite, rGO served as an electronic accelerator to faciliate the separation of electrons and the transfer of photogenerated electrons, and the Z-scheme heterojunction of $\mathrm{g}-\mathrm{C}_{3} \mathrm{~N}_{4} / \mathrm{BiVO}_{4}$ also promoted the charge transfer and inhibited the recombination of electron-hole pairs. As a result, the ternary composite achieved the complete degradation of $\mathrm{Rh} B$ in 20 min under visible light irradiation, which was much faster than $\mathrm{rGO} / \mathrm{BiVO}_{4}$ and pure $\mathrm{g}-\mathrm{C}_{3} \mathrm{~N}_{4}$. Li et al. [144] prepared a $\mathrm{BiVO}_{4} / \mathrm{rGO} / \mathrm{Ag}_{3} \mathrm{PO}_{4}$ ternary photocatalyst by a two-step method. The composite with the optimized ratio of $\mathrm{Ag}_{3} \mathrm{PO}_{4}$ and $\mathrm{BiVO}_{4} / \mathrm{rGO}$ exhibited the best photocatalytic performance for the degradation of $\mathrm{Rh} \mathrm{B}$ and 4-nitrophenol, which was due to the synergistic effect of $\mathrm{Ag}_{3} \mathrm{PO}_{4}$ and $\mathrm{BiVO}_{4}$. Meanwhile, the rGO sheets strengthened the interficial interaction of different components and accelerated the transfer and separation of photogenerated carriers at their interfaces.

In view of the superior magnetization and stability of $\mathrm{Mn}_{1-\mathrm{x}} \mathrm{Zn}_{\mathrm{x}} \mathrm{Fe}_{2} \mathrm{O}_{4}$, Xie et al. [145] prepared a magnetic $\mathrm{BiVO}_{4} / \mathrm{Mn}_{1-\mathrm{x}} \mathrm{Zn}_{\mathrm{x}} \mathrm{Fe}_{2} \mathrm{O}_{4} / \mathrm{rGO}$ photocatalyst by a simple calcination and reduction method. The ternary composite showed an enhanced photocatalytic activity for the degradation of Rh B under visible light, with a repeatable degradation activity after being reused for five cycles. In another work, Chen et al. [146] synthesized a novel Z-scheme $\mathrm{Ag} / \mathrm{Ag}_{3} \mathrm{PO}_{4} / \mathrm{BiVO}_{4} / \mathrm{rGO}$ nanocomposite photocatalyst by an in situ deposition and photoreduction method. The composite displayed a photodegradation efficiency of $94.96 \%$ for the removal of TC in 60 min, which was much better than $\mathrm{BiVO}_{4}$ and $\mathrm{Ag}_{3} \mathrm{PO}_{4}$. As presented in Figure 9a, the high photoactivity can be attributed to the strong absorption capability, high surface area, and fast separation efficiency of electron-hole pairs caused by the co-catalytic effect between $\mathrm{Ag} / \mathrm{Ag}_{3} \mathrm{PO}_{4}$ and $\mathrm{rGO}$. Similar to $\mathrm{BiVO}_{4}, \mathrm{BiOX}$ has a superior photocatalytic activity. $\mathrm{Su}$ et al. [147] prepared a $\mathrm{BiOCl} / \mathrm{BiOI} / \mathrm{rGO}$ composite photocatalyst by a one-step solvothermal method (Figure $9 \mathrm{~b}$ ). The addition of $\mathrm{GO}$ changed the microstructure of $50 \% \mathrm{BiOCl} / \mathrm{BiOI}$ from microspheres to hollow microspheres, which increased the light absorption. Moreover, the strong interfacial interaction formed between $\mathrm{rGO}$ and $50 \% \mathrm{BiOCl} / \mathrm{BiOI}$ significantly improved the photocatalytic efficiency for the degradation of Rh B. 


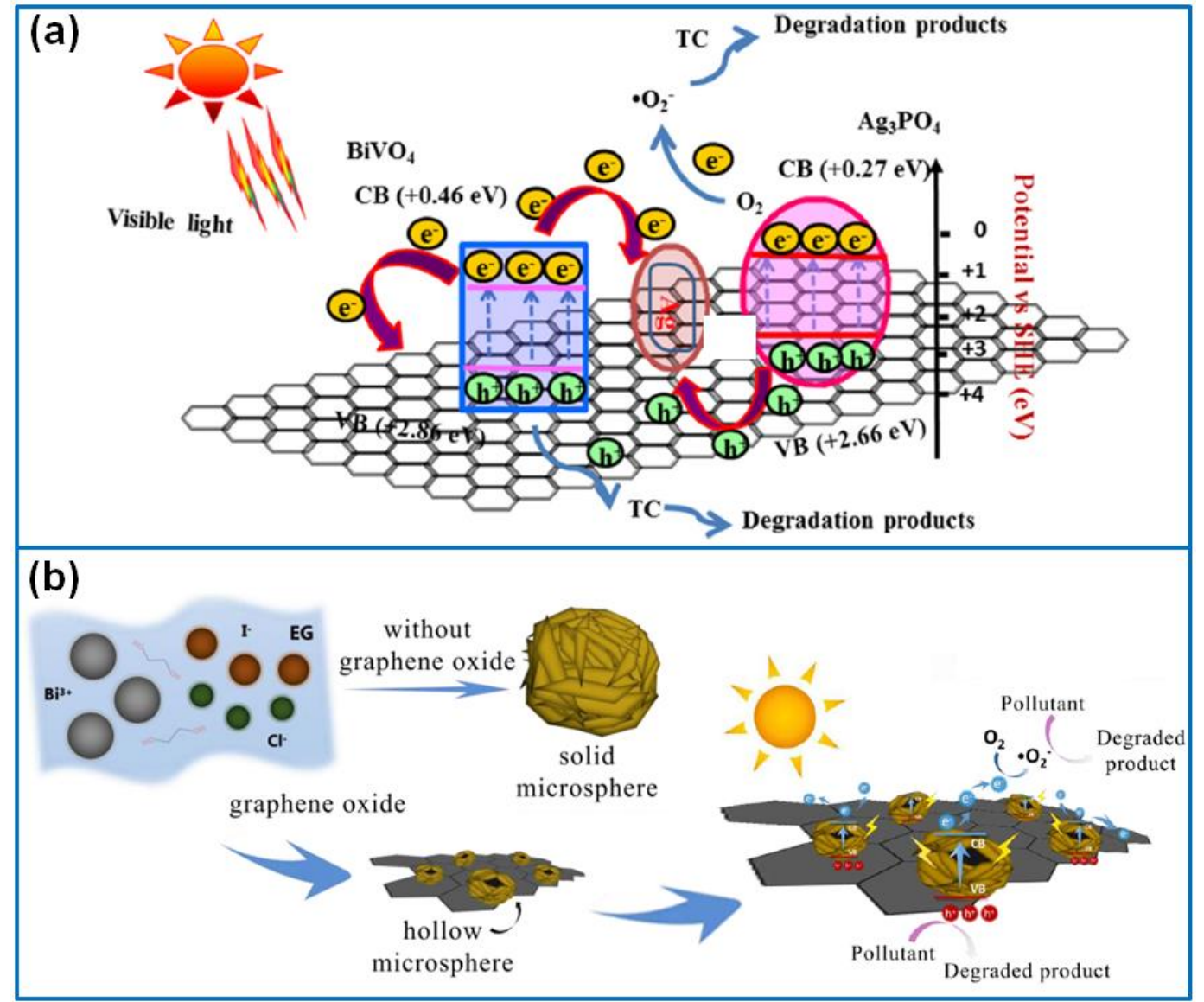

Figure 9. (a) Photocatalytic mechanism of $\mathrm{Z}$-scheme $\mathrm{Ag} / \mathrm{Ag}_{3} \mathrm{PO}_{4} / \mathrm{BiVO}_{4} / \mathrm{rGO}$ nanocomposite; produced with permission [146]. Copyright 2017, Elsevier. (b) Preparation of BiOCl/BiOI/rGO composite photocatalyst; produced with permission [147]. Copyright 2018, Elsevier.

To sum up, we introduce the application progress of graphene/metal oxide ternary composites, including graphene/ $\mathrm{TiO}_{2^{-}}$, graphene/ZnO-, graphene $/ \mathrm{SnO}_{2^{-}}$, graphene $/ \mathrm{Cu}_{2} \mathrm{O}_{-}$, graphene $/ \mathrm{Fe}_{\mathrm{x}} \mathrm{O}_{\mathrm{y}^{-}}$, and graphene/Bi-containing ternary composite photocatalysts, as summarized in Table S7. In the composition of ternary composites, except for the graphene matrix, the combination of metal oxide with noble metal nanoparticles, such as $\mathrm{Au}, \mathrm{Ag}, \mathrm{Pd}$, and $\mathrm{Pt}$ is a practical strategy to improve the photocatalytic performance. The result has confirmed that the Au-doping of $\mathrm{WO}_{3} / \mathrm{TiO}_{2}$ even displays a higher photocatalytic activity than that of $\mathrm{WO}_{3} / \mathrm{TiO}_{2} / \mathrm{rGO}$, which further reflects the importance of noble metal doping. In addition, the formation of $n-n$ type or $p-n$ type heterojunctions is a promising approach to design high-performance graphene/metal oxides ternary composites. The formed heterojunction expands the light absorption by adjusting the band gap and efficiently transfers the photoinduced electrons and holes, thus suppressing the recombination of photogenerated electron-hole pairs. Therefore, the matching of components and the proportion optimization are the major tasks for enhancing the photocatalytic performance of ternary composites. Besides traditional metal oxides, such as, $\mathrm{SnO}_{2}, \mathrm{TiO}_{2}, \mathrm{ZnO}, \mathrm{WO}_{3}, \mathrm{Cu}_{2} \mathrm{O}, \mathrm{Fe}_{2} \mathrm{O}_{3}, \mathrm{~V}_{2} \mathrm{O}_{5}, \mathrm{CeO}_{2}[148], \mathrm{Nb}_{2} \mathrm{O}_{5}, \mathrm{NiO}, \mathrm{Co}_{3} \mathrm{O}_{4}, \mathrm{MoO}_{3}$, and $\mathrm{In}_{2} \mathrm{O}_{3}$, some special metal oxides including $\mathrm{BiVO}_{4}, \mathrm{Ag}_{3} \mathrm{PO}_{4}$, and $\mathrm{BiOX}$ are the better candidate materials to prepare high-performance ternary composite photocatalysts.

\section{Conclusions and Outlook}

In summary, recent progress on the graphene/metal oxide photocatalysts are summarized in detail. Compared to individual metal oxides, graphene-based binary or ternary composites present superior photocatalytic efficiency for the synergistic effect of different components. In terms of 
photocatalytic mechanism, the conductive graphene nanosheets not only expand the visible or UV light adsorption range by adjusting the band gap of metal oxides, but they also inhibit the recombination of photogenerated electron-hole pairs by accelerating the interfacial charge transfer. Various chemical and physical methods are adopted to synthesize graphene/metal oxide composites and control the microstructure of metal oxides. The purpose of the microstructure design is to introduce much more active sites and increase the specific surface area of the composite, which facilitates the adsorption and surface contact between the organic molecules and the semiconductor. Therefore, the microstructure of metal oxides or graphene has an important influence on the photocatalytic performance. For example, the nanorings, quantum dots, mesoporous structure, hirarchical nanoflowers, hollow spheres, and 3D porous framework have presented an outstanding photocatalytic activity. In addition, the heteroatom doping of metal oxides, introduction of metal nanoparticles, or forming heterojunctions will change the band gap and efficiently transfer the photogenerated electrons or holes, thus enhancing the photocatalytic efficiency of the composite. Regarding the selection of metal oxides, the coupling of graphene with $\mathrm{TiO}_{2}, \mathrm{ZnO}$, and $\mathrm{SnO}_{2}$ has the best proportion of easy preparation, low cost, and high performance. However, there are seldom reports about transition metal oxides such as $\mathrm{V}_{2} \mathrm{O}_{5}, \mathrm{CeO}_{2}$, $\mathrm{Nb}_{2} \mathrm{O}_{5}, \mathrm{NiO}, \mathrm{Co}_{3} \mathrm{O}_{4}, \mathrm{MoO}_{3}$, and $\mathrm{In}_{2} \mathrm{O}_{3}$. Compared to binary composites, graphene/metal oxide ternary composites have been widely developed in recent years due to their greater diversity and novelty. The research topics have been focused on the matching of different metal oxides, microstructure design, and the composition optimization. In the design of graphene-based ternary composites, it is a practical strategy for the hybridization of metal oxide with noble metal nanoparticles including $\mathrm{Au}, \mathrm{Ag}, \mathrm{Pd}$, and Pt. In addition, the fabrication of $n-n$ type or $p-n$ type heterojunctions is the major idea to develop high-performance ternary composite photocatalysts. Various ternary composites are introduced in detail, including graphene/ $\mathrm{TiO}_{2-}^{-}$, graphene/ $\mathrm{ZnO}-$, graphene $/ \mathrm{SnO}_{2^{-}}$, graphene $/ \mathrm{Cu}_{2} \mathrm{O}-$, graphene/ $/ \mathrm{Fe}_{\mathrm{x}} \mathrm{O}_{\mathrm{y}^{-}}$, and graphene/Bi-containing ternary composites, and the third component can be selected from the noble metal nanoparticles and transition metal oxides, such as $\mathrm{V}_{2} \mathrm{O}_{5}, \mathrm{Fe}_{2} \mathrm{O}_{3}, \mathrm{Fe}_{3} \mathrm{O}_{4}$, $\mathrm{In}_{2} \mathrm{O}_{3}, \mathrm{Cu}_{2} \mathrm{O}, \mathrm{Bi}_{2} \mathrm{O}_{3}, \mathrm{CoFe}_{2} \mathrm{O}_{4}, \mathrm{Zn}_{2} \mathrm{SnO}_{4}, \mathrm{BiVO}_{4}, \mathrm{BiOX}$, and seval sulfides, including $\mathrm{ZnS}$ and $\mathrm{SnS}_{2}$. The formed heterojunction expands the light absorption by adjusting the band gap and efficiently transfers the photoinduced electrons and holes, thus suppressing the recombination of photogenerated electron-hole pairs. Therefore, those ternary composites have been developed and presented an outstanding photocatalytic performance.

Although great progress have been achieved in the field of graphene/metal oxides photocatalysts, there are still some challenges to develop novel high-performance composite photocatalysts, such as controllable synthesis, microstructure design, the matching of different components, and the exploration of photodegradation mechanisms. The existing problems just provide several research directions for the researchers. (1) Adjusting the band gap of metal oxide through hybridization. Each metal oxide has a different value of band gap, so the selection of different metal oxides should consider the range of the valence band and conduction band. The suitable combination of metal oxides with other materials will effectively expand the light absorption range. Meanwhile, the formation of heterojunctions also faciliates the transfer of photoinduced electrons and holes. (2) Exploring the relationship between the photocatalytic efficiency and the microstructure of graphene or metal oxides. The microstructure of graphene, including quantum dots, a sheet-like structure or a free-standing framework, as well as the morphology of metal oxides, has a significant influence on the photocatalytic activity of composites. The porous structure with a large specific surface area often exhibits higher photocatalytic efficiency through increasing the adsorption acitive sites for anchoring organic molecules. (3) Disclosing the novel photocatalytic mechanism of graphene-based ternary composites. Except for the graphene substrate, graphene-based ternary composites have more chances for selecting the third component, for example, the combination of metal nanoparticles with metal oxides, and the formation of $n-n$ type, $p-n$ type, and $p-p$ type heterojunctions. Different combinations will result in an unexpected performance. However, how to explain the role of each component is difficult. Therefore, 
disclosing the photocatalytic mechanism of novel ternary composites is a major research topic in the photocatalysis field.

Supplementary Materials: The following are available online at http://www.mdpi.com/2073-4344/10/8/921/s1, Table S1: The performance of graphene/ $/ \mathrm{TiO}_{2}$ composite in degradation of organic dyes; Table S2: The performance of graphene/ZnO composite in degradation of organic dyes; Table S3: The performance of graphene/ $\mathrm{SnO}_{2}$ composite in degradation of organic dyes; Table S4: The performance of graphene/ $\mathrm{WO}_{3}$ composite in degradation of organic dyes; Table S5: The performance of graphene $/ \mathrm{Fe}_{2} \mathrm{O}_{3}$ composite in degradation of organic dyes; Table S6: The performance of graphene/other metal oxides in degradation of organic dyes; Table S7: The performance of graphene-based ternary composite in degradation of organic dyes.

Author Contributions: Conceptualization, X.H.; methodology, J.F.; Writing, X.W. and Y.L.; validation, B.L. All authors have read and agreed to the published version of the manuscript.

Funding: This research was funded by National Natural Science Foundation of China (51403094), and Program of Liaoning Education Department of China (No. LJ2017FBL002).

Conflicts of Interest: The authors declare no conflict of interest.

\section{References}

1. Boczkaj, G.; Fernandes, A. Wastewater treatment by means of advanced oxidation processes at basic $\mathrm{pH}$ conditions: A review. Chem. Eng. J. 2017, 320, 608-633. [CrossRef]

2. Djurišić, A.B.; Leung, Y.H.; Ching Ng, A.M. Strategies for improving the efficiency of semiconductor metal oxide photocatalysis. Mater. Horiz. 2014, 1, 400-410. [CrossRef]

3. Haque, F.; Daeneke, T.; Kalantar-zadeh, K.; Ou, J.Z. Two-Dimensional Transition Metal Oxide and Chalcogenide-Based Photocatalysts. Nano Micro Lett. 2017, 10, 23. [CrossRef] [PubMed]

4. Singh, N.; Prakash, J.; Gupta, R.K. Design and engineering of high-performance photocatalytic systems based on metal oxide-graphene-noble metal nanocomposites. Mol. Syst. Des. Eng. 2017, 2, 422-439. [CrossRef]

5. Li, X.; Shen, R.; Ma, S.; Chen, X.; Xie, J. Graphene-based heterojunction photocatalysts. Appl. Surf. Sci. 2018, 430, 53-107. [CrossRef]

6. Guo, Q.; Zhou, C.; Ma, Z.; Yang, X. Fundamentals of $\mathrm{TiO}_{2}$ Photocatalysis: Concepts, Mechanisms, and Challenges. Adv. Mater. 2019, 31, 1901997. [CrossRef] [PubMed]

7. Khalid, N.R.; Ahmed, E.; Hong, Z.; Sana, L.; Ahmed, M. Enhanced photocatalytic activity of graphene-TiO composite under visible light irradiation. Curr. Appl. Phys. 2013, 13, 659-663. [CrossRef]

8. Liang, Y.; Wang, H.; Sanchez Casalongue, H.; Chen, Z.; Dai, H. TiO 2 nanocrystals grown on graphene as advanced photocatalytic hybrid materials. Nano Res. 2010, 3, 701-705. [CrossRef]

9. Liu, J.; Wang, L.; Tang, J.; Ma, J. Photocatalytic degradation of commercially sourced naphthenic acids by $\mathrm{TiO}_{2}$-graphene composite nanomaterial. Chemosphere 2016, 149, 328-335. [CrossRef]

10. Haldorai, Y.; Rengaraj, A.; Kwak, C.H.; Huh, Y.S.; Han, Y.-K. Fabrication of nano $\mathrm{TiO}_{2} @$ graphene composite: Reusable photocatalyst for hydrogen production, degradation of organic and inorganic pollutants. Synth. Met. 2014, 198, 10-18. [CrossRef]

11. Ton, N.N.T.; Dao, A.T.N.; Kato, K.; Ikenaga, T.; Trinh, D.X.; Taniike, T. One-pot synthesis of $\mathrm{TiO}_{2}$ /graphene nanocomposites for excellent visible light photocatalysis based on chemical exfoliation method. Carbon 2018, 133, 109-117. [CrossRef]

12. Zhu, P.; Nair, A.S.; Shengjie, P.; Shengyuan, Y.; Ramakrishna, S. Facile Fabrication of $\mathrm{TiO}_{2}-\mathrm{Graphene}$ Composite with Enhanced Photovoltaic and Photocatalytic Properties by Electrospinning. ACS Appl. Mater. Interfaces 2012, 4, 581-585. [CrossRef] [PubMed]

13. Pu, S.; Zhu, R.; Ma, H.; Deng, D.; Pei, X.; Qi, F.; Chu, W. Facile in-situ design strategy to disperse $\mathrm{TiO}_{2}$ nanoparticles on graphene for the enhanced photocatalytic degradation of rhodamine 6G. Appl. Catal. B-Environ. 2017, 218, 208-219. [CrossRef]

14. Guimarães de Oliveira, A.; Nascimento, J.P.; de Fátima Gorgulho, H.; Martelli, P.B.; Furtado, C.A.; Figueiredo, J.L. Electrochemical synthesis of $\mathrm{TiO}_{2} /$ Graphene oxide composite films for photocatalytic applications. J. Alloys Compd. 2016, 654, 514-522. [CrossRef]

15. Khan, S.A.; Arshad, Z.; Shahid, S.; Arshad, I.; Rizwan, K.; Sher, M.; Fatima, U. Synthesis of $\mathrm{TiO}_{2} /$ Graphene oxide nanocomposites for their enhanced photocatalytic activity against methylene blue dye and ciprofloxacin. Compos. Part B Eng. 2019, 175, 107120. [CrossRef] 
16. Morawski, A.W.; Kusiak-Nejman, E.; Wanag, A.; Kapica-Kozar, J.; Wróbel, R.J.; Ohtani, B.; Aksienionek, M.; Lipińska, L. Photocatalytic degradation of acetic acid in the presence of visible light-active $\mathrm{TiO}_{2}$-reduced graphene oxide photocatalysts. Catal. Today 2017, 280, 108-113. [CrossRef]

17. Yang, J.; Wen, Z.; Shen, X.; Dai, J.; Li, Y.; Li, Y. A comparative study on the photocatalytic behavior of graphene- $\mathrm{TiO}_{2}$ nanostructures: Effect of $\mathrm{TiO}_{2}$ dimensionality on interfacial charge transfer. Chem. Eng. J. 2018, 334, 907-921. [CrossRef]

18. Yang, Y.; Xu, L.; Wang, H.; Wang, W.; Zhang, L. $\mathrm{TiO}_{2} /$ graphene porous composite and its photocatalytic degradation of methylene blue. Mater. Des. 2016, 108, 632-639. [CrossRef]

19. Trapalis, A.; Todorova, N.; Giannakopoulou, T.; Boukos, N.; Speliotis, T.; Dimotikali, D.; Yu, J. TiO $2 /$ graphene composite photocatalysts for NOx removal: A comparison of surfactant-stabilized graphene and reduced graphene oxide. Appl. Catal. B Environ. 2016, 180, 637-647. [CrossRef]

20. Rajender, G.; Kumar, J.; Giri, P.K. Interfacial charge transfer in oxygen deficient $\mathrm{TiO}_{2}$-graphene quantum dot hybrid and its influence on the enhanced visible light photocatalysis. Appl. Catal. B Environ. 2018, 224, 960-972. [CrossRef]

21. Lee, J.S.; You, K.H.; Park, C.B. Highly Photoactive, Low Bandgap $\mathrm{TiO}_{2}$ Nanoparticles Wrapped by Graphene. Adv. Mater. 2012, 24, 1084-1088. [CrossRef] [PubMed]

22. Lui, G.; Liao, J.-Y.; Duan, A.; Zhang, Z.; Fowler, M.; Yu, A. Graphene-wrapped hierarchical $\mathrm{TiO}_{2}$ nanoflower composites with enhanced photocatalytic performance. J. Mater. Chem. A 2013, 1, 12255-12262. [CrossRef]

23. Zhang, J.; Zhu, Z.; Tang, Y.; Feng, X. Graphene encapsulated hollow $\mathrm{TiO}_{2}$ nanospheres: Efficient synthesis and enhanced photocatalytic activity. J. Mater. Chem. A 2013, 1, 3752-3756. [CrossRef]

24. Brindha, A.; Sivakumar, T. Visible active N, $\mathrm{S}$ co-doped $\mathrm{TiO}_{2} /$ graphene photocatalysts for the degradation of hazardous dyes. J. Photochem. Photobiol. A Chem. 2017, 340, 146-156. [CrossRef]

25. Dai, K.; Lu, L.; Liu, Q.; Zhu, G.; Liu, Q.; Liu, Z. Graphene oxide capturing surface-fluorinated $\mathrm{TiO}_{2}$ nanosheets for advanced photocatalysis and the reveal of synergism reinforce mechanism. Dalton Trans. 2014, 43, 2202-2210. [CrossRef] [PubMed]

26. Inturi, S.N.R.; Boningari, T.; Suidan, M.; Smirniotis, P.G. Visible-light-induced photodegradation of gas phase acetonitrile using aerosol-made transition metal (V, Cr, Fe, Co, Mn, Mo, Ni, Cu, Y, Ce, and Zr) doped $\mathrm{TiO}_{2}$. Appl. Catal. B Environ. 2014, 144, 333-342. [CrossRef]

27. Isari, A.A.; Payan, A.; Fattahi, M.; Jorfi, S.; Kakavandi, B. Photocatalytic degradation of rhodamine B and real textile wastewater using Fe-doped $\mathrm{TiO} 2$ anchored on reduced graphene oxide $\left(\mathrm{Fe}-\mathrm{TiO}_{2} / \mathrm{rGO}\right)$ : Characterization and feasibility, mechanism and pathway studies. Appl. Surf. Sci. 2018, 462, 549-564. [CrossRef]

28. Zhang, Z.; Xiao, F.; Guo, Y.; Wang, S.; Liu, Y. One-Pot Self-Assembled Three-Dimensional TiO ${ }_{2}-G_{r a p h e n e}$ Hydrogel with Improved Adsorption Capacities and Photocatalytic and Electrochemical Activities. ACS Appl. Mater. Inter. 2013, 5, 2227-2233. [CrossRef]

29. Zhang, J.; Li, S.; Tang, B.; Wang, Z.; Ji, G.; Huang, W.; Wang, J. High Photocatalytic Performance of Two Types of Graphene Modified TiO2 Composite Photocatalysts. Nanoscale Res. Lett. 2017, 12, 457. [CrossRef]

30. Atchudan, R.; Edison, T.N.J.I.; Perumal, S.; Karthikeyan, D.; Lee, Y.R. Facile synthesis of zinc oxide nanoparticles decorated graphene oxide composite via simple solvothermal route and their photocatalytic activity on methylene blue degradation. J. Photochem. Photobiol. B 2016, 162, 500-510. [CrossRef]

31. Zhu, L.; Liu, Z.; Xia, P.; Li, H.; Xie, Y. Synthesis of hierarchical ZnO\&Graphene composites with enhanced photocatalytic activity. Ceram. Int. 2018, 44, 849-856.

32. Moussa, H.; Girot, E.; Mozet, K.; Alem, H.; Medjahdi, G.; Schneider, R. ZnO rods/reduced graphene oxide composites prepared via a solvothermal reaction for efficient sunlight-driven photocatalysis. Appl. Catal. $B$ Environ. 2016, 185, 11-21. [CrossRef]

33. Zhang, D.; Zhao, Y.; Chen, L. Fabrication and characterization of amino-grafted graphene oxide modified ZnO with high photocatalytic activity. Appl. Surf. Sci. 2018, 458, 638-647. [CrossRef]

34. Luo, Q.-P.; Yu, X.-Y.; Lei, B.-X.; Chen, H.-Y.; Kuang, D.-B.; Su, C.-Y. Reduced Graphene Oxide-Hierarchical ZnO Hollow Sphere Composites with Enhanced Photocurrent and Photocatalytic Activity. J. Phys. Chem. C 2012, 116, 8111-8117. [CrossRef]

35. Zarrabi, M.; Haghighi, M.; Alizadeh, R. Sonoprecipitation dispersion of ZnO nanoparticles over graphene oxide used in photocatalytic degradation of methylene blue in aqueous solution: Influence of irradiation time and power. Ultrason. Sonochem. 2018, 48, 370-382. [CrossRef] 
36. Víctor-Román, S.; García-Bordejé, E.; Hernández-Ferrer, J.; González-Domínguez, J.M.; Ansón-Casaos, A.; Silva, A.M.T.; Maser, W.K.; Benito, A.M. Controlling the surface chemistry of graphene oxide: Key towards efficient ZnO-GO photocatalysts. Catal. Today 2019. [CrossRef]

37. Maruthupandy, M.; Qin, P.; Muneeswaran, T.; Rajivgandhi, G.; Quero, F.; Song, J.-M. Graphene-zinc oxide nanocomposites (G-ZnO NCs): Synthesis, characterization and their photocatalytic degradation of dye molecules. Mater. Sci. Eng. B 2020, 254, 114516. [CrossRef]

38. Gayathri, S.; Jayabal, P.; Kottaisamy, M.; Ramakrishnan, V. Synthesis of ZnO decorated graphene nanocomposite for enhanced photocatalytic properties. J. Appl. Phys. 2014, 115, 173504. [CrossRef]

39. Jin, X.; Ma, Z.; Liu, G.; Hu, D.; Song, C.; Huang, Q. In-situ ionothermal precipitation of well-dispersed $\mathrm{ZnO}$ nanoparticles onto 2-dimension neat graphene sheets with excellent photocatalytic activity. J. Environ. Chem. Eng. 2020, 8, 104030. [CrossRef]

40. Reddy, T.N.; Manna, J.; Rana, R.K. Polyamine-Mediated Interfacial Assembly of rGO-ZnO Nanostructures: A Bio-inspired Approach and Enhanced Photocatalytic Properties. ACS Appl. Mater. Interfaces 2015, 7, 19684-19690. [CrossRef]

41. Pruna, A.; Wu, Z.; Zapien, J.A.; Li, Y.Y.; Ruotolo, A. Enhanced photocatalytic performance of ZnO nanostructures by electrochemical hybridization with graphene oxide. Appl. Surf. Sci. 2018, 441, 936-944. [CrossRef]

42. Xue, B.; Zou, Y. High photocatalytic activity of ZnO-graphene composite. J. Colloid Interf. Sci. 2018, 529, 306-313. [CrossRef] [PubMed]

43. Lonkar, S.P.; Pillai, V.; Abdala, A. Solvent-free synthesis of ZnO-graphene nanocomposite with superior photocatalytic activity. Appl. Surf. Sci. 2019, 465, 1107-1113. [CrossRef]

44. Yao, C.; Xie, A.; Shen, Y.; Zhu, W.; Zhu, J. Graphene oxide used as a surfactant to induce the flower-like ZnO microstructures: Growth mechanism and enhanced photocatalytic properties. Cryst. Res. Technol. 2014, 49, 982-989. [CrossRef]

45. Zhao, Y.; Liu, L.; Cui, T.; Tong, G.; Wu, W. Enhanced photocatalytic properties of ZnO/reduced graphene oxide sheets (rGO) composites with controllable morphology and composition. Appl. Surf. Sci. 2017, 412, 58-68. [CrossRef]

46. Li, B.; Liu, T.; Wang, Y.; Wang, Z. ZnO/graphene-oxide nanocomposite with remarkably enhanced visible-light-driven photocatalytic performance. J. Colloid Interface Sci. 2012, 377, 114-121. [CrossRef]

47. Xu, T.; Zhang, L.; Cheng, H.; Zhu, Y. Significantly enhanced photocatalytic performance of ZnO via graphene hybridization and the mechanism study. Appl. Catal. B Environ. 2011, 101, 382-387. [CrossRef]

48. Xu, J.; Cui, Y.; Han, Y.; Hao, M.; Zhang, X. ZnO-graphene composites with high photocatalytic activities under visible light. RSC Adv. 2016, 6, 96778-96784. [CrossRef]

49. Van Thuan, D.; Nguyen, T.K.; Kim, S.-W.; Chung, J.S.; Hur, S.H.; Kim, E.J.; Hahn, S.H.; Wang, M. Chemical-hydrothermal synthesis of oval-shaped graphene/ZnO quantum hybrids and their photocatalytic performances. Catal. Commun. 2017, 101, 102-106. [CrossRef]

50. Kumar, S.; Dhiman, A.; Sudhagar, P.; Krishnan, V. ZnO-graphene quantum dots heterojunctions for natural sunlight-driven photocatalytic environmental remediation. Appl. Surf. Sci. 2018, 447, 802-815. [CrossRef]

51. Thuan, D.V.; Khoa, N.T.; Kim, S.W.; Yoo, D.-H.; Kim, E.J.; Hahn, S.H. Photoluminescence Properties and Photocatalytic Performance of Different Size ZnO NanoparticlesDecorated Graphene Oxide. J. Nanosci. Nanotechnol. 2015, 15, 8896-8900. [CrossRef] [PubMed]

52. Tayyebi, A.; Outokesh, M.; Tayebi, M.; Shafikhani, A.; Şengör, S.S. ZnO quantum dots-graphene composites: Formation mechanism and enhanced photocatalytic activity for degradation of methyl orange dye. J. Alloys Compd. 2016, 663, 738-749. [CrossRef]

53. Bai, X.; Wang, L.; Zong, R.; Lv, Y.; Sun, Y.; Zhu, Y. Performance Enhancement of ZnO Photocatalyst via Synergic Effect of Surface Oxygen Defect and Graphene Hybridization. Langmuir 2013, 29, 3097-3105. [CrossRef] [PubMed]

54. Ramos-Corona, A.; Rangel, R.; Alvarado-Gil, J.J.; Bartolo-Pérez, P.; Quintana, P.; Rodríguez-Gattorno, G. Photocatalytic performance of nitrogen doped $\mathrm{ZnO}$ structures supported on graphene oxide for $\mathrm{MB}$ degradation. Chemosphere 2019, 236, 124368. [CrossRef] [PubMed]

55. Hsieh, S.-H.; Ting, J.-M. Characterization and photocatalytic performance of ternary Cu-doped ZnO/Graphene materials. Appl. Surf. Sci. 2018, 427, 465-475. [CrossRef] 
56. Cai, R.; Wu, J.-G.; Sun, L.; Liu, Y.-J.; Fang, T.; Zhu, S.; Li, S.-Y.; Wang, Y.; Guo, L.-F.; Zhao, C.-E.; et al. 3D graphene/ZnO composite with enhanced photocatalytic activity. Mater. Des. 2016, 90, 839-844. [CrossRef]

57. Men, X.; Chen, H.; Chang, K.; Fang, X.; Wu, C.; Qin, W.; Yin, S. Three-dimensional free-standing ZnO/graphene composite foam for photocurrent generation and photocatalytic activity. Appl. Catal. B Environ. 2016, 187, 367-374. [CrossRef]

58. Rokhsat, E.; Akhavan, O. Improving the photocatalytic activity of graphene oxide/ZnO nanorod films by UV irradiation. Appl. Surf. Sci. 2016, 371, 590-595. [CrossRef]

59. Jiang, H.; Wang, R.; Wang, D.; Hong, X.; Yang, S. SnO 2 /Diatomite Composite Prepared by Solvothermal Reaction for Low-Cost Photocatalysts. Catalysts 2019, 9, 1060. [CrossRef]

60. Chen, H.; Pu, X.; Gu, M.; Zhu, J.; Cheng, L. Tailored synthesis of $\mathrm{SnO}_{2} @$ graphene nanocomposites with enhanced photocatalytic response. Ceram. Int. 2016, 42, 17717-17722. [CrossRef]

61. Chen, L.-Y.; Zhang, W.-D.; Xu, B.; Yu, Y.-X. A Facile Hydrothermal Strategy for Synthesis of $\mathrm{SnO}_{2}$ Nanorods-Graphene Nanocomposites for High Performance Photocatalysis. J. Nanosci. Nanotechnol. 2012, 12, 6921-6929. [CrossRef] [PubMed]

62. Shyamala, R.; Gomathi Devi, L. Reduced graphene oxide/SnO $\mathrm{S}_{2}$ nanocomposites for the photocatalytic degradation of rhodamine B: Preparation, characterization, photosensitization, vectorial charge transfer mechanism and identification of reaction intermediates. Chem. Phys. Lett. 2020, 748, 137385. [CrossRef]

63. Tajima, T.; Goto, H.; Nishi, M.; Ohkubo, T.; Nishina, Y.; Miyake, H.; Takaguchi, Y. A facile synthesis of a $\mathrm{SnO}_{2} /$ Graphene oxide nano-nano composite and its photoreactivity. Mater. Chem. Phys. 2018, 212, 149-154. [CrossRef]

64. Kim, T.; Parale, V.G.; Jung, H.-N.-R.; Kim, Y.; Driss, Z.; Driss, D.; Bouabidi, A.; Euchy, S.; Park, H.-H. Facile Synthesis of $\mathrm{SnO}_{2}$ Aerogel/Reduced Graphene Oxide Nanocomposites via in Situ Annealing for the Photocatalytic Degradation of Methyl Orange. Nanomaterials 2019, 9, 358. [CrossRef] [PubMed]

65. Chen, Y.; Sun, F.; Huang, Z.; Chen, H.; Zhuang, Z.; Pan, Z.; Long, J.; Gu, F. Photochemical fabrication of $\mathrm{SnO}_{2}$ dense layers on reduced graphene oxide sheets for application in photocatalytic degradation of p-Nitrophenol. Appl. Catal. B Environ. 2017, 215, 8-17. [CrossRef]

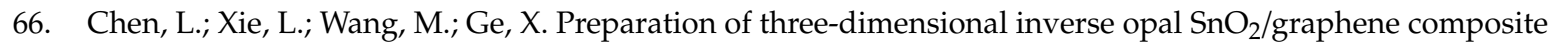
microspheres and their enhanced photocatalytic activities. J. Mater. Chem. A 2015, 3, 2991-2998. [CrossRef]

67. Tang, L.; Nguyen, V.H.; Lee, Y.R.; Kim, J.; Shim, J.-J. Photocatalytic activity of reduced graphene oxide/SnO 2 nanocomposites prepared in ionic liquid. Synth. Met. 2015, 201, 54-60. [CrossRef]

68. Cao, Y.; Li, Y.; Jia, D.; Xie, J. Solid-state synthesis of $\mathrm{SnO}_{2}$-graphene nanocomposite for photocatalysis and formaldehyde gas sensing. RSC Adv. 2014, 4, 46179-46186. [CrossRef]

69. Xie, Y.; Yu, S.; Zhong, Y.; Zhang, Q.; Zhou, Y. SnO 2 /graphene quantum dots composited photocatalyst for efficient nitric oxide oxidation under visible light. Appl. Surf. Sci. 2018, 448, 655-661. [CrossRef]

70. Wei, J.; Xue, S.; Xie, P.; Zou, R. Synthesis and photocatalytic properties of different $\mathrm{SnO}_{2}$ microspheres on graphene oxide sheets. Appl. Surf. Sci. 2016, 376, 172-179. [CrossRef]

71. Sephra, P.J.; Baraneedharan, P.; Sivakumar, M.; Thangadurai, T.D.; Nehru, K. Size controlled synthesis of $\mathrm{SnO}_{2}$ and its electrostatic self- assembly over reduced graphene oxide for photocatalyst and supercapacitor application. Mater. Res. Bull. 2018, 106, 103-112. [CrossRef]

72. Shen, H.; Zhao, X.; Duan, L.; Liu, R.; Wu, H.; Hou, T.; Jiang, X.; Gao, H. Influence of interface combination of RGO-photosensitized $\mathrm{SnO}_{2} @ \mathrm{RGO}$ core-shell structures on their photocatalytic performance. Appl. Surf. Sci. 2017, 391, 627-634. [CrossRef]

73. Hong, X.; Wang, R.; Li, S.; Fu, J.; Chen, L.; Wang, X. Hydrophilic macroporous $\mathrm{SnO}_{2} / \mathrm{rGO}$ composite prepared by melamine template for high efficient photocatalyst. J. Alloys Compd. 2020, 816, 152550. [CrossRef]

74. Ben Haj Othmen, W.; Hamdi, A.; Addad, A.; Sieber, B.; Elhouichet, H.; Szunerits, S.; Boukherroub, R. Fe-doped $\mathrm{SnO}_{2}$ decorated reduced graphene oxide nanocomposite with enhanced visible light photocatalytic activity. J. Photochem. Photobio. A 2018, 367, 145-155. [CrossRef]

75. Paik, T.; Cargnello, M.; Gordon, T.R.; Zhang, S.; Yun, H.; Lee, J.D.; Woo, H.Y.; Oh, S.J.; Kagan, C.R.; Fornasiero, P.; et al. Photocatalytic Hydrogen Evolution from Substoichiometric Colloidal $\mathrm{WO}_{3}-\mathrm{x}$ Nanowires. ACS Energy Lett. 2018, 3, 1904-1910. [CrossRef]

76. Tie, L.; Yu, C.; Zhao, Y.; Chen, H.; Yang, S.; Sun, J.; Dong, S.; Sun, J. Fabrication of $\mathrm{WO}_{3}$ nanorods on reduced graphene oxide sheets with augmented visible light photocatalytic activity for efficient mineralization of dye. J. Alloys Compd. 2018, 769, 83-91. [CrossRef] 
77. Fu, L.; Xia, T.; Zheng, Y.; Yang, J.; Wang, A.; Wang, Z. Preparation of $\mathrm{WO}_{3}$-reduced graphene oxide nanocomposites with enhanced photocatalytic property. Ceram. Int. 2015, 41, 5903-5908. [CrossRef]

78. Gan, L.; Xu, L.; Shang, S.; Zhou, X.; Meng, L. Visible light induced methylene blue dye degradation photo-catalyzed by $\mathrm{WO}_{3}$ /graphene nanocomposites and the mechanism. Ceram. Int. 2016, 42, 15235-15241. [CrossRef]

79. Khan, M.E.; Khan, M.M.; Cho, M.H. Fabrication of WO3 nanorods on graphene nanosheets for improved visible light-induced photocapacitive and photocatalytic performance. RSC Adv. 2016, 6, 20824-20833. [CrossRef]

80. Khan, M.Y.; Ahmad, M.; Sadaf, S.; Iqbal, S.; Nawaz, F.; Iqbal, J. Visible light active indigo dye/graphene/WO 3 nanocomposites with excellent photocatalytic activity. J. Mater. Res. Technol. 2019, 8, 3261-3269. [CrossRef]

81. Ismail, A.A.; Faisal, M.; Al-Haddad, A. Mesoporous $\mathrm{WO}_{3}$-graphene photocatalyst for photocatalytic degradation of Methylene Blue dye under visible light illumination. J. Environ. Sci. 2018, 66, 328-337. [CrossRef] [PubMed]

82. Zhou, M.; Yan, J.; Cui, P. Synthesis and enhanced photocatalytic performance of $\mathrm{WO}_{3}$ nanorods @ graphene nanocomposites. Mater. Lett. 2012, 89, 258-261. [CrossRef]

83. Huang, H.; Yue, Z.; Li, G.; Wang, X.; Huang, J.; Du, Y.; Yang, P. Ultraviolet-assisted preparation of mesoporous $\mathrm{WO}_{3}$ /reduced graphene oxide composites: Superior interfacial contacts and enhanced photocatalysis. J. Mater. Chem. A 2013, 1, 15110-15116. [CrossRef]

84. Jeevitha, G.; Abhinayaa, R.; Mangalaraj, D.; Ponpandian, N. Tungsten oxide-graphene oxide $\left(\mathrm{WO}_{3}-\mathrm{GO}\right)$ nanocomposite as an efficient photocatalyst, antibacterial and anticancer agent. J. Phys. Chem. Solids 2018, 116, 137-147. [CrossRef]

85. Guo, J.; Li, Y.; Zhu, S.; Chen, Z.; Liu, Q.; Zhang, D.; Moon, W.-J.; Song, D.-M. Synthesis of $W_{3} @ G r a p h e n e$ composite for enhanced photocatalytic oxygen evolution from water. RSC Adv. 2012, 2, 1356-1363. [CrossRef]

86. Nasim, M.N.E.A.A.; Chun, D.-M. Formation of few-layer graphene flake structures from graphite particles during thin film coating using dry spray deposition method. Thin Solid Film 2017, 622, 34-40. [CrossRef]

87. Hossain, S.; Chu, W.-S.; Lee, C.S.; Ahn, S.-H.; Chun, D.-M. Photocatalytic performance of few-layer Graphene/ $\mathrm{WO}_{3}$ thin films prepared by a nano-particle deposition system. Mater. Chem. Phys. 2019, 226, 141-150. [CrossRef]

88. Mishra, M.; Chun, D.-M. $\alpha-\mathrm{Fe}_{2} \mathrm{O}_{3}$ as a photocatalytic material: A review. Appl. Catal. A-Gen. 2015, 498, 126-141. [CrossRef]

89. Pradhan, G.K.; Padhi, D.K.; Parida, K.M. Fabrication of $\alpha-\mathrm{Fe}_{2} \mathrm{O}_{3}$ Nanorod/RGO Composite: A Novel Hybrid Photocatalyst for Phenol Degradation. ACS Appl. Mater. Interfaces 2013, 5, 9101-9110. [CrossRef]

90. Han, S.; Hu, L.; Liang, Z.; Wageh, S.; Al-Ghamdi, A.A.; Chen, Y.; Fang, X. One-Step Hydrothermal Synthesis of 2D Hexagonal Nanoplates of $\alpha$-Fe2O3/Graphene Composites with Enhanced Photocatalytic Activity. Adv. Funct. Mater. 2014, 24, 5719-5727. [CrossRef]

91. Mohan, B.S.; Ravi, K.; Anjaneyulu, R.B.; Sree, G.S.; Basavaiah, K. Fe2O3/RGO nanocomposite photocatalyst: Effective degradation of 4-Nitrophenol. Physica B 2019, 553, 190-194. [CrossRef]

92. Zhang, L.; Hu, H.; Wu, M.; Yu, X.; Sun, Z.; Li, G.; Liu, X.; Zheng, X. A novel bubbling-assisted exfoliating method preparation of magnetically separable $\gamma-\mathrm{Fe}_{2} \mathrm{O}_{3}$ /graphene recyclable photocatalysts. Funct. Mater. Lett. 2014, 7, 1450056. [CrossRef]

93. Wang, F. Magnetically recoverable $\mathrm{Fe}_{2} \mathrm{O}_{3} / \mathrm{N}$-graphene with enhanced visible photocatalytic performance. Chem. Eng. Res. Des. 2019, 142, 189-194. [CrossRef]

94. Wang, H.; Raziq, F.; Qu, Y.; Qin, C.; Wang, J.; Jing, L. Role of quaternary N in N-doped graphene- $\mathrm{Fe}_{2} \mathrm{O}_{3}$ nanocomposites as efficient photocatalysts for $\mathrm{CO}_{2}$ reduction and acetaldehyde degradation. RSC Adv. 2015, 5, 85061-85064. [CrossRef]

95. Kumar, S.; Parlett, C.M.A.; Isaacs, M.A.; Jowett, D.V.; Douthwaite, R.E.; Cockett, M.C.R.; Lee, A.F. Facile synthesis of hierarchical $\mathrm{Cu}_{2} \mathrm{O}$ nanocubes as visible light photocatalysts. Appl. Catal. B Environ. 2016, 189, 226-232. [CrossRef]

96. Wang, A.; Li, X.; Zhao, Y.; Wu, W.; Chen, J.; Meng, H. Preparation and characterizations of $\mathrm{Cu}_{2} \mathrm{O} / \mathrm{reduced}$ graphene oxide nanocomposites with high photo-catalytic performances. Powder Technol. 2014, 261, 42-48. [CrossRef]

97. Zhang, D.; Yang, J.; Wang, J.; Yang, J.; Qiao, G. Construction of $\mathrm{Cu}_{2} \mathrm{O}$-reduced graphene oxide composites with enhanced photoelectric and photocatalytic properties. Opt. Mater. 2020, 100, 109612. [CrossRef] 
98. Liu, S.-H.; Wei, Y.-S.; Lu, J.-S. Visible-light-driven photodegradation of sulfamethoxazole and methylene blue by $\mathrm{Cu}_{2} \mathrm{O} / \mathrm{rGO}$ photocatalysts. Chemosphere 2016, 154, 118-123. [CrossRef]

99. Liu, X.; Zeng, J.; Yang, H.; Zhou, K.; Pan, D. $\mathrm{V}_{2} \mathrm{O}_{5}$-Based nanomaterials: Synthesis and their applications. RSC Adv. 2018, 8, 4014-4031. [CrossRef]

100. Shanmugam, M.; Alsalme, A.; Alghamdi, A.; Jayavel, R. Enhanced Photocatalytic Performance of the Graphene- $\mathrm{V}_{2} \mathrm{O}_{5}$ Nanocomposite in the Degradation of Methylene Blue Dye under Direct Sunlight. ACS Appl. Mater. Interfaces 2015, 7, 14905-14911. [CrossRef]

101. Aawani, E.; Memarian, N.; Dizaji, H.R. Synthesis and characterization of reduced graphene oxide- $\mathrm{V}_{2} \mathrm{O}_{5}$ nanocomposite for enhanced photocatalytic activity under different types of irradiation. J. Phys. Chem. Solids 2019, 125, 8-15. [CrossRef]

102. Huang, K.; Li, Y.H.; Lin, S.; Liang, C.; Xu, X.; Zhou, Y.F.; Fan, D.Y.; Yang, H.J.; Lang, P.L.; Zhang, R.; et al. One-step synthesis of reduced graphene oxide- $\mathrm{CeO}_{2}$ nanocubes composites with enhanced photocatalytic activity. Mater. Lett. 2014, 124, 223-226. [CrossRef]

103. Qi, S.; Fei, L.; Zuo, R.; Wang, Y.; Wu, Y. Graphene nanocluster decorated niobium oxide nanofibers for visible light photocatalytic applications. J. Mater. Chem. A 2014, 2, 8190-8195. [CrossRef]

104. Ahmad, J.; Majid, K.; Dar, M.A. Controlled synthesis of p-type NiO/n-type GO nanocomposite with enhanced photocatalytic activity and study of temperature effect on the photocatalytic activity of the nanocomposite. Appl. Surf. Sci. 2018, 457, 417-426. [CrossRef]

105. Bin, Z.; Hui, L. Three-dimensional porous graphene- $\mathrm{Co}_{3} \mathrm{O}_{4}$ nanocomposites for high performance photocatalysts. Appl. Surf. Sci. 2015, 357, 439-444. [CrossRef]

106. Ramar, V.; Balasubramanian, K. Optical and highly enhanced solar light-driven photocatalytic activity of reduced graphene oxide wrapped $\alpha-\mathrm{MoO}_{3}$ nanoplates. Sol. Energy 2019, 194, 1-10. [CrossRef]

107. Ding, M.; Huang, H.; Yang, P. Preparation and Visible Light Photocatalytic Performance of Ordered Mesoporous Indium Dioxide/Reduced Graphene Oxide Nanocomposite. Chem. J. Chin. Univ. 2015, 36, 989-995.

108. Orlov, A.; Jefferson, D.A.; Macleod, N.; Lambert, R.M. Photocatalytic Properties of $\mathrm{TiO}_{2}$ Modified with Gold Nanoparticles in the Degradation of 4-Chlorophenol in Aqueous Solution. Catal. Lett. 2004, 92, 41-47. [CrossRef]

109. Safajou, H.; Khojasteh, H.; Salavati-Niasari, M.; Mortazavi-Derazkola, S. Enhanced photocatalytic degradation of dyes over graphene/Pd/TiO 2 nanocomposites: $\mathrm{TiO}_{2}$ nanowires versus $\mathrm{TiO}_{2}$ nanoparticles. J. Colloid Interface Sci. 2017, 498, 423-432. [CrossRef]

110. Zhao, W.; Zhang, Z.; Zhang, J.; Wu, H.; Xi, L.; Ruan, C. Synthesis of Ag/ $\mathrm{TiO}_{2} /$ graphene and its photocatalytic properties under visible light. Mater. Lett. 2016, 171, 182-186. [CrossRef]

111. Leong, K.H.; Sim, L.C.; Bahnemann, D.; Jang, M.; Ibrahim, S.; Saravanan, P. Reduced graphene oxide and Ag wrapped $\mathrm{TiO}_{2}$ photocatalyst for enhanced visible light photocatalysis. APL Mater. 2015, 3, 104503. [CrossRef]

112. Ghasemi, S.; Hashemian, S.J.; Alamolhoda, A.A.; Gocheva, I.; Rahman Setayesh, S. Plasmon enhanced photocatalytic activity of $\mathrm{Au} @ \mathrm{TiO}_{2}$-graphene nanocomposite under visible light for degradation of pollutants. Mater. Res. Bull. 2017, 87, 40-47. [CrossRef]

113. Biaduń, E.; Gajewska, S.; Miecznikowski, K.; Krasnodebska-Ostrega, B. Application of Hierarchical Nanostructured $\mathrm{WO}_{3}$ and $\mathrm{Fe}_{2} \mathrm{O}_{3}$ Composites for Photodegradation of Surfactants in Water Samples. Catalysts 2019, 9, 1039. [CrossRef]

114. Zeng, X.; Wang, Z.; Wang, G.; Gengenbach, T.R.; McCarthy, D.T.; Deletic, A.; Yu, J.; Zhang, X. Highly dispersed $\mathrm{TiO}_{2}$ nanocrystals and $\mathrm{WO}_{3}$ nanorods on reduced graphene oxide: Z-scheme photocatalysis system for accelerated photocatalytic water disinfection. Appl. Catal. B Environ. 2017, 218, 163-173. [CrossRef]

115. Zhang, Y.-q.; Li, X.-h.; Lü, J.; Si, C.-d.; Liu, G.-j.; Gao, H.-t.; Wang, P.-b. A ternary $\mathrm{TiO}_{2} / \mathrm{WO}_{3} /$ graphene nanocomposite adsorbent: Facile preparation and efficient removal of Rhodamine B. Int. J. Min. Metall. Mater. 2014, 21, 813-819. [CrossRef]

116. He, F.; Meng, A.; Cheng, B.; Ho, W.; Yu, J. Enhanced photocatalytic H2-production activity of $\mathrm{WO}_{3} / \mathrm{TiO}_{2}$ step-scheme heterojunction by graphene modification. Chin. J. Catal. 2020, 41, 9-20. [CrossRef]

117. Guo, S.-Y.; Dai, J.-G.; Zhao, T.-J.; Hou, S.-D.; Zhang, P.; Wang, P.-G.; Sun, G.-X. A novel microporous amorphous-ZnO@ $\mathrm{TiO}_{2} /$ graphene ternary nanocomposite with enhanced photocatalytic activity. RSC Adv. 2017, 7, 36787-36792. [CrossRef] 
118. Iliev, V.; Tomova, D.; Bilyarska, L. Promoting the oxidative removal rate of 2,4-dichlorophenoxyacetic acid on gold-doped $\mathrm{WO}_{3} / \mathrm{TiO}_{2} /$ reduced graphene oxide photocatalysts under UV light irradiation. J. Photochem. Photobiol. A 2018, 351, 69-77. [CrossRef]

119. Wang, S.; Xu, M.; Peng, T.; Zhang, C.; Li, T.; Hussain, I.; Wang, J.; Tan, B. Porous hypercrosslinked polymer- $\mathrm{TiO}_{2}$-graphene composite photocatalysts for visible-light-driven $\mathrm{CO}_{2}$ conversion. Nature Commun. 2019, 10, 676. [CrossRef]

120. Huang, Y.; Chen, D.; Hu, X.; Qian, Y.; Li, D. Preparation of $\mathrm{TiO}_{2} /$ Carbon Nanotubes/Reduced Graphene Oxide Composites with Enhanced Photocatalytic Activity for the Degradation of Rhodamine B. Nanomaterials 2018, 8, 431. [CrossRef]

121. Nanakkal, A.R.; Alexander, L.K. Graphene/BiVO4/TiO 2 nanocomposite: Tuning band gap energies for superior photocatalytic activity under visible light. J. Mater. Sci. 2017, 52, 7997-8006. [CrossRef]

122. Huang, J.; Fu, K.; Deng, X.; Yao, N.; Wei, M. Fabrication of $\mathrm{TiO}_{2}$ Nanosheet Aarrays/Graphene/Cu $2 \mathrm{O}$ Composite Structure for Enhanced Photocatalytic Activities. Nanoscale Res. Lett. 2017, 12, 310. [CrossRef] [PubMed]

123. Chang, J.S.; Strunk, J.; Chong, M.N.; Poh, P.E.; Ocon, J.D. Multi-dimensional zinc oxide (ZnO) nanoarchitectures as efficient photocatalysts: What is the fundamental factor that determines photoactivity in $\mathrm{ZnO}$ ? J. Hazard. Mater. 2020, 381, 120958. [CrossRef]

124. Ahmad, M.; Ahmed, E.; Hong, Z.L.; Khalid, N.R.; Ahmed, W.; Elhissi, A. Graphene-Ag/ZnO nanocomposites as high performance photocatalysts under visible light irradiation. J. Alloys Compd. 2013, 577, 717-727. [CrossRef]

125. Zhu, P.; Chen, Y.; Duan, M.; Liu, M.; Zou, P.; Zhou, M. Enhanced visible photocatalytic activity of $\mathrm{Fe}-\mathrm{Cu}-\mathrm{ZnO} /$ graphene oxide photocatalysts for the degradation of organic dyes. Can. J. Chem. Eng. 2018, 96, 1479-1488. [CrossRef]

126. Kheirabadi, M.; Samadi, M.; Asadian, E.; Zhou, Y.; Dong, C.; Zhang, J.; Moshfegh, A.Z. Well-designed $\mathrm{Ag} / \mathrm{ZnO} / 3 \mathrm{D}$ graphene structure for dye removal: Adsorption, photocatalysis and physical separation capabilities. J. Colloid Interface Sci. 2019, 537, 66-78. [CrossRef]

127. Mu, H.; Gu, Y.; Xie, H. Photocatalysis of Nickel-Based Graphene/Au/ZnO Nanocomposites. IEEE Sens. J. 2019, 19, 5376-5388. [CrossRef]

128. Li, Y.; Wang, L.; Ge, J.; Wang, J.; Li, Q.; Wan, W.; Zhang, B.; Liu, X.; Xue, W. Graphene quantum dots modified $\mathrm{ZnO}+\mathrm{Cu}$ heterostructure photocatalysts with enhanced photocatalytic performance. RSC Adv. 2016, 6, 106508-106515. [CrossRef]

129. Wang, Z.; Luo, C.; Zhang, Y.; Gong, Y.; Wu, J.; Fu, Q.; Pan, C. Construction of hierarchical $\mathrm{TiO}_{2}$ nanorod array/graphene/ZnO nanocomposites for high-performance photocatalysis. J. Mater. Sci. 2018, 53, 15376-15389. [CrossRef]

130. Lonkar, S.P.; Pillai, V.V.; Alhassan, S.M. Facile and scalable production of heterostructured ZnS-ZnO/Graphene nano-photocatalysts for environmental remediation. Sci. Rep. 2018, 8, 13401. [CrossRef]

131. Yu, X.; Zhang, G.; Cao, H.; An, X.; Wang, Y.; Shu, Z.; An, X.; Hua, F. ZnO@ZnS hollow dumbbells- graphene composites as high-performance photocatalysts and alcohol sensors. New J. Chem. 2012, 36, 2593-2598. [CrossRef]

132. Shandilya, P.; Sudhaik, A.; Raizada, P.; Hosseini-Bandegharaei, A.; Singh, P.; Rahmani-Sani, A.; Thakur, V.; Saini, A.K. Synthesis of $\mathrm{Eu} 3+-$ doped $\mathrm{ZnO} / \mathrm{Bi}_{2} \mathrm{O}_{3}$ heterojunction photocatalyst on graphene oxide sheets for visible light-assisted degradation of 2,4-dimethyl phenol and bacteria killing. Solid State Sci. 2020, 102, 106164. [CrossRef]

133. Zhang, L.; Hu, X.; Zhu, L.; Jin, X.; Feng, C. Water-dispersible ZnO/COFe ${ }_{2} \mathrm{O}_{4} /$ graphene photocatalyst and their high-performance in water treatment. Fuller. Nanotub. Carbon Nanostruct. 2019, 27, 873-877. [CrossRef]

134. Kar, A.; Olszówka, J.; Sain, S.; Sloman, S.-R.I.; Montes, O.; Fernández, A.; Pradhan, S.K.; Wheatley, A.E.H. Morphological effects on the photocatalytic properties of $\mathrm{SnO}_{2}$ nanostructures. J. Alloys Compd. 2019, 810, 151718. [CrossRef]

135. Mohanta, D.; Ahmaruzzaman, M. A novel Au-SnO $2-r G O$ ternary nanoheterojunction catalyst for UV-LED induced photocatalytic degradation of clothianidin: Identification of reactive intermediates, degradation pathway and in-depth mechanistic insight. J. Hazard. Mater. 2020, 397, 122685. [CrossRef] 
136. Wang, Z.; Du, Y.; Zhang, F.; Zheng, Z.; Zhang, X.; Feng, Q.; Wang, C. Photocatalytic degradation of pendimethalin over $\mathrm{Cu}_{2} \mathrm{O} / \mathrm{SnO}_{2}$ /graphene and $\mathrm{SnO}_{2}$ /graphene nanocomposite photocatalysts under visible light irradiation. Mater. Chem. Phys. 2013, 140, 373-381. [CrossRef]

137. Li, Y.; Wu, X.; Ho, W.; Lv, K.; Li, Q.; Li, M.; Lee, S.C. Graphene-induced formation of visible-light-responsive $\mathrm{SnO}_{2}-\mathrm{Zn}_{2} \mathrm{SnO}_{4} \mathrm{Z}$-scheme photocatalyst with surface vacancy for the enhanced photoreactivity towards $\mathrm{NO}$ and acetone oxidation. Chem. Eng. J. 2018, 336, 200-210. [CrossRef]

138. Huang, R.; Wu, C.; Huang, S.; Chen, D.; Zhang, Q.; Wang, Q.; Hu, Z.; Jiang, Y.; Zhao, B.; Chen, Z. Construction of $\mathrm{SnS}_{2}-\mathrm{SnO}_{2}$ heterojunctions decorated on graphene nanosheets with enhanced visible-light photocatalytic performance. Acta Crystallogr. C 2019, 75, 812-821. [CrossRef]

139. Liu, J.; Ke, J.; Li, D.; Sun, H.; Liang, P.; Duan, X.; Tian, W.; Tadé, M.O.; Liu, S.; Wang, S. Oxygen Vacancies in Shape Controlled $\mathrm{Cu}_{2} \mathrm{O} /$ Reduced Graphene Oxide/In2O3 Hybrid for Promoted Photocatalytic Water Oxidation and Degradation of Environmental Pollutants. ACS Appl. Mater. Interfaces 2017, 9, 11678-11688. [CrossRef]

140. Yan, Z.; Xu, Z.; Yang, Z.; Yue, L.; Huang, L. Graphene oxide/Fe2O3 nanoplates supported Pt for enhanced room-temperature oxidation of formaldehyde. Appl. Surf. Sci. 2019, 467, 277-285. [CrossRef]

141. Boruah, P.K.; Szunerits, S.; Boukherroub, R.; Das, M.R. Magnetic $\mathrm{Fe}_{3} \mathrm{O}_{4} @ \mathrm{~V}_{2} \mathrm{O}_{5} / \mathrm{rGO}$ nanocomposite as a recyclable photocatalyst for dye molecules degradation under direct sunlight irradiation. Chemosphere 2018, 191, 503-513. [CrossRef] [PubMed]

142. Malathi, A.; Madhavan, J.; Ashokkumar, M.; Arunachalam, P. A review on $\mathrm{BiVO}_{4}$ photocatalyst: Activity enhancement methods for solar photocatalytic applications. Appl. Catal. A Gen. 2018, 555, 47-74.

143. Zhang, Q.; Liu, M.; Liu, S.; Qiao, L.; Hu, X.; Tian, H. Z-scheme g- $\mathrm{C}_{3} \mathrm{~N}_{4} / \mathrm{BiVO}_{4}$ photocatalysts with $\mathrm{RGO}$ as electron transport accelerator. J. Mater. Sci. Mater. Electron. 2020, 31, 667-676. [CrossRef]

144. Li, Y.; Xiao, X.; Ye, Z. Fabrication of $\mathrm{BiVO}_{4} / \mathrm{RGO} / \mathrm{Ag}_{3} \mathrm{PO}_{4}$ ternary composite photocatalysts with enhanced photocatalytic performance. Appl. Surf. Sci. 2019, 467, 902-911. [CrossRef]

145. Xie, T.; Li, H.; Liu, C.; Yang, J.; Xiao, T.; Xu, L. Magnetic Photocatalyst $\mathrm{BiVO}_{4} / \mathrm{Mn}-\mathrm{Zn}$ ferrite/Reduced Graphene Oxide: Synthesis Strategy and Its Highly Photocatalytic Activity. Nanomaterials 2018, 8, 380. [CrossRef]

146. Chen, F.; Yang, Q.; Li, X.; Zeng, G.; Wang, D.; Niu, C.; Zhao, J.; An, H.; Xie, T.; Deng, Y. Hierarchical assembly of graphene-bridged $\mathrm{Ag}_{3} \mathrm{PO}_{4} / \mathrm{Ag} / \mathrm{BiVO}_{4}(040) \mathrm{Z}$-scheme photocatalyst: An efficient, sustainable and heterogeneous catalyst with enhanced visible-light photoactivity towards tetracycline degradation under visible light irradiation. Appl. Catal. B Environ. 2017, 200, 330-342. [CrossRef]

147. Su, X.; Yang, J.; Yu, X.; Zhu, Y.; Zhang, Y. In situ grown hierarchical 50\%BiOCl/BiOI hollow flowerlike microspheres on reduced graphene oxide nanosheets for enhanced visible-light photocatalytic degradation of rhodamine B. Appl. Surf. Sci. 2018, 433, 502-512. [CrossRef]

148. Tizhoosh, N.Y.; Khataee, A.; Hassandoost, R.; Soltani, R.D.C.; Doustkhah, E. Ultrasound-engineered synthesis of $\mathrm{WS}_{2} @ \mathrm{CeO}_{2}$ heterostructure for sonocatalytic degradation of tylosin. Ultrason. Sonochem. 2020, 67, 105114. [CrossRef]

(C) 2020 by the authors. Licensee MDPI, Basel, Switzerland. This article is an open access article distributed under the terms and conditions of the Creative Commons Attribution (CC BY) license (http://creativecommons.org/licenses/by/4.0/). 